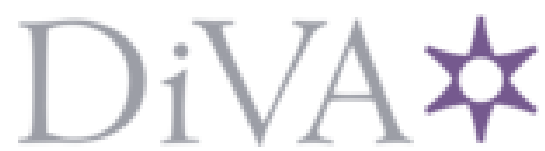

http://www.diva-portal.org

\title{
Preprint
}

This is the submitted version of a paper published in Energy Journal.

Citation for the original published paper (version of record):

Taliotis, C., Taibi, E., Howells, M., Rogner, H., Bazilian, M. et al. [Year unknown!]

Renewable Energy Technology integration for the island of Cyprus: A cost-optimization approach.

Energy Journal

Access to the published version may require subscription.

N.B. When citing this work, cite the original published paper.

Permanent link to this version:

http://urn.kb.se/resolve?urn=urn:nbn:se:kth:diva-206756 


\section{Renewable Energy Technology integration for the island of Cyprus: A cost-optimization approach}

Constantinos Taliotis ${ }^{\mathrm{a}^{*}}$, Emanuele Taibi ${ }^{\mathrm{b}+}$, Mark Howells ${ }^{\mathrm{a}}$, Holger Rogner ${ }^{\mathrm{a}}$, Morgan Bazilian ${ }^{\mathrm{a}}$, Manuel Welsch ${ }^{\mathrm{a}}$

${ }^{a} \mathrm{KTH}$ - Royal Institute of Technology, division of Energy Systems Analysis Office K514, Brinellvägen 68, 10044 Stockholm, Sweden

Tel: +46764098119

*taliotis@kth.se

${ }^{b}$ International Renewable Energy Agency (IRENA), Robert Schuman Platz 3, 53111, Bonn

+ETaibi@irena.org

\section{$\underline{\text { Abstract }}$}

In light of the ongoing financial crisis, Cyprus is called to transform its energy sector. The high electricity cost has been recognized as a priority issue and authorities on the island are considering several available options to reduce electricity tariffs. A fuel switch from oil to gas, domestic or imported, an electrical cross-border interconnection and a rapid increase in the share of renewable energy are among the major options being considered. Focusing on the power supply of Cyprus, the present study uses a cost-optimization tool to investigate the impact of different combinations of policy decision, resulting in a series of different scenarios, with some common key findings, with the aim of directly informing future energy policy decisions. Results indicate that renewable energy technologies will play a major role regardless the decisions taken. However, a set of enabling regulatory and market changes on the horizon might prevent least-cost deployment of renewables to take place. This study will review the findings and make some recommendations on the achievement of this optimal pathways for the evolution of Cyprus electricity sector.

Keywords: Renewable energy; cost-optimization; Cyprus; power supply optimisation; scenarios; energy policy; electricity markets; MESSAGE.

\section{Introduction}

The Republic of Cyprus is confronted with significant decisions about how energy infrastructure, particularly in the power sector, should develop in the coming decades. As this island-country presently imports all of its required oil products, attempts are underway to reduce this import dependency through the development of domestic energy resources. The continued reduction in the cost of renewable energy technologies, coupled with abundant renewable energy potential, provides the opportunity for reducing the island's dependency on fossil fuels while complying with EU renewable energy targets for 2020 and achieving the national aspirational goals for 2030.

There are certain aspects that make the case of Cyprus particularly interesting. First, the electricity supply system of the island is completely isolated, as there are currently no interconnections to the electrical grids of neighbouring countries (a grid interconnection, the EuroAsia Interconnector, between Israel, Cyprus and Greece is currently under investigation [1]). Therefore, Cyprus needs to meet its electricity demand at all times using domestic generation resources, and faces more challenges for integrating a high share of variable renewable energy technologies in the power grid, due to the low inherent flexibility of the system.

At present, thermal power generation in Cyprus relies on heavy fuel oil (HFO) and to a lesser extent diesel. Both fuels are imported, which exposes the price of electricity to international oil price fluctuations. In the current low oil price environment in early 2015, power system planning may be 
induced into maintaining such a reliance on HFO. On the other hand, recent discoveries of offshore natural gas reserves in the exclusive economic zone of Cyprus might eliminate the necessity for importing oil products for generating electricity, improving the trade balance and reducing cost of power generation. The extent of the estimated volumes of potential gas reserves provide a strong incentive for the government to evaluate a range of options, including the prospect of exports, for which an onshore gas liquefaction terminal was the key option discussed in 2014. It is presently expected that production of indigenous natural gas could commence by 2022 .

In order to reduce the price of electricity until domestic natural gas extraction commences, the Government of Cyprus is considering an interim solution, in which gas may be imported up to 2023, due to its comparatively lower price than oil and the ability to use existing highly efficient combined cycle gas turbines. However, important investments in infrastructure (for instance, a regasification terminal or gas pipelines from Israeli offshore gas fields to the power plants) will be required in such a scenario.

Due to the uncertainty and risk associated with any such set of decisions, energy planners must consider a wide set of scenarios. The primary aim of this paper is to examine the cost-competitiveness and provide insights on the future role of renewable energy technologies in the electricity mix, ensuring a cost-optimal power supply mix that takes into account policy targets. The paper can be considered as an academic summary of an assessment conducted directly for the Ministry of Energy, Commerce, Industry and Tourism (MECIT) of the Republic of Cyprus [2], in response to a request for assistance to the International Renewable Energy Agency (IRENA). The impetus for the analysis includes three main drivers. The policy driver is the EU renewable energy target for Cyprus in 2020 (Directive 2009/28/EC), and the country's own aspirational targets for 2030. The economic driver is the need to reduce the high power generation cost that has been observed in recent years on the island [3]. The geopolitical driver is linked to the reduction of import dependency so as to strengthen the country's energy security.

An optimization model, based on WASP, has previously been employed to examine effects on the country's electricity cost by the set 2020 renewable energy target [4]. This model focused solely on electricity generation. Additionally, a model of Cyprus for the entire energy system exists within a regional model, which is used for informing energy policy decisions of the European Union [5]. However, not all the assumptions used are clearly stated, which does not allow replication of the analysis. In the present study, a quantitative assessment making use of a cost-optimization approach is employed to investigate plausible pathways for the development of the power sector in Cyprus for a set of scenarios. To this end, building on existing work [6], an electricity supply model is developed using the long-term energy modelling platform called Model for Energy Supply Strategy Alternatives and their General Environmental Impact (MESSAGE) [7].

Section 2 of the paper presents the basic structure of the constructed model and describes the scenarios that have been formulated for the purposes of this study. In addition, since a model's outputs are heavily reliant on the inputs, the key assumptions are briefly discussed in this section. Main results and a scenario comparison are shown in section 3, while a short sensitivity analysis is also included. In section 4 the key insights that can be extracted from the results are discussed along with highlights regarding implications for policy makers. The paper ends with a summary of the study's conclusions in section 5 . 


\section{Methodology}

\subsection{Model development}

The analysis is based on a previously developed model [6] and constructed in MESSAGE [7] ${ }^{1}$. MESSAGE is a dynamic multi-period optimization model for medium to long term energy system planning, energy policy analysis and scenario development. It minimizes total discounted energy system cost while ensuring that all energy demands, system constraints and policy objectives are met. It does so by accounting for the vintage structure of the stock of existing plant and equipment and related infrastructure, the domestic energy resource endowment, energy trade links and prices, specific technology options for both capacity expansion and replacement of retired units, and relevant energy policy constraints and objectives. The model is a web of chains linking energy sources, supply, transmission and demand-side technologies, thus enabling the user to construct a mathematical image of an energy system, i.e., from resource extraction to final energy use (Figure 1).

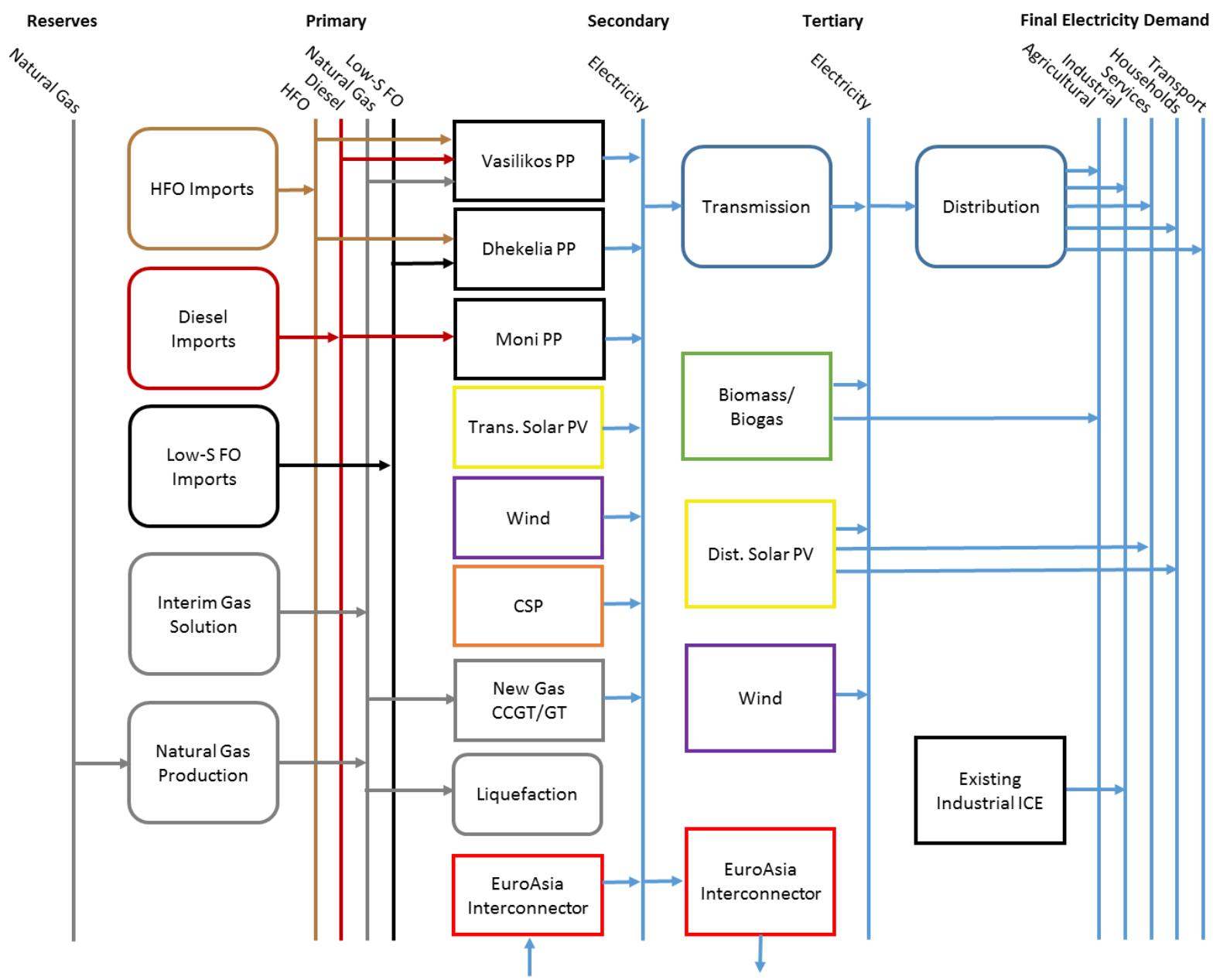

Figure 1. Simplified Reference Energy System of the Cyprus power sector.

\footnotetext{
${ }^{1}$ MESSAGE, originally developed at the International Institute for Applied Systems Analysis (IIASA), has been widely applied for global energy assessments and climate change mitigation analyses. The model is also used by the International Atomic Energy Agency (IAEA) for energy planning capacity building and numerous national and regional energy systems analyses in IAEA Member States.
} 
In order to allow for a more detailed representation of the power infrastructure on the island, the model is updated to account for all existing and future power generating technologies. Thermal power plants are disaggregated by fuel and technology (e.g. steam turbine, gas turbine etc.).

\subsection{Current system status, future plans and key assumptions}

The most recent installations of Combined Cycle Gas Turbines increased the total installed power generation capacity to approximately $1685 \mathrm{MW}$, of which $1478 \mathrm{MW}$ are operated by the Electricity Authority of Cyprus at the sites of Vasilikos, Dhekelia and Moni (

Table 1). This capacity provides a sizable reserve margin; recorded fifteen-minute peak demand transmission system generation was just below $1000 \mathrm{MW}$ in 2012 and $815 \mathrm{MW}$ in 2013 (total load approximated as 839 MW - Transmission System Operator - Cyprus, 2014b, 2014c). Recently, reserve capacity has increased due to the economic downturn and its dampening effect on electricity demand; maximum system demand in 2010 was $1148 \mathrm{MW}$ [10].

Once natural gas becomes available, either through domestic production or an interim solution, as a result of provisions made in the plant, the units at the Vasilikos site can switch to this fuel instead of diesel and heavy fuel oil. As such, infrastructure already exists in place to accommodate for the potential arrival of this fuel.

Beyond the existing installed technologies, there are a number of additions that are either committed or assessed. These include a committed wind installation of $30 \mathrm{MW}$, a committed solar thermal (CSP) facility of $50 \mathrm{MW}$ with graphite as a storage medium (for 12 hours), and an expected annual installation of $15 \mathrm{MW}$ up to 2020 in solar PV under a net metering scheme ${ }^{2}$. For the purposes of this study and after indications from the Ministry of Energy, Commerce, Industry and Tourism (MECIT), the net metering annual additions of $15 \mathrm{MW}$ are considered as committed projects in all scenarios. This is based on the assumption that the savings offered through net metering will be recognized by utility customers and the maximum threshold will be reached in all years until 2020 .

Table 1. Total installed capacity at the end of 2013 [11], [12]

\begin{tabular}{llcc}
\hline Installation & Type of Technology & Fuel & Capacity (MW) \\
\hline Vasilikos & Combined Cycle Gas Turbine & Diesel & 440 \\
& Steam Turbine $^{2}$ & Heavy Fuel Oil & 390 \\
Dhekelia & Gas Turbine & Diesel & 38 \\
Moni & Steam Turbine $^{3}$ & Heavy Fuel Oil & 360 \\
Vasilikos Cement & Internal Combustion Engine & 100 \\
Skouriotissa Mine & Gas Turbine $^{5}$ & Heavy Fuel Oil & 150 \\
Larnaca Airport & Internal Combustion Engine & Diesel & 6 \\
Wind & Internal Combustion Engine & Heavy Fuel Oil & 6.72 \\
Wind & Internal Combustion Engine & Diesel & 6.4 \\
Biomass/biomass & connected to Transmission & Diesel & 144.3 \\
PV & connected to Distribution & --- & 2.4 \\
& connected to Distribution & --- & 9.7 \\
\hline
\end{tabular}

${ }^{1}$ Consists of 4 gas turbine ( $75 \mathrm{MW}$ each) and 2 steam turbine units (70 MW each)

${ }^{2}$ Consists of 3 units of $130 \mathrm{MW}$ each.

${ }^{3}$ Consists of 6 units of $60 \mathrm{MW}$ each.

${ }^{4}$ Consists of 6 units of approximately 16 MW each.

${ }^{5}$ Consists of 4 units of $37.5 \mathrm{MW}$ each.

\footnotetext{
${ }^{2}$ In the past, the Republic of Cyprus had in place the highest Feed-in Tariff for solar PV in the European Union [13], but at present new installations fall under a net metering scheme, if eligible.
} 
${ }^{6}$ Does not include the net metering systems; this value as of September 2014 is greater than $45 \mathrm{MW}$ with an increasing trend

\subsubsection{Demand projections}

Final electricity demand projections are taken from a separate assessment developed as part of the IRENA assistance to Cyprus, developed by the Cyprus University of Technology (CUT) [2]. Projections, based on an econometric model, for eight different categories of consumers are aggregated to five (transport, industrial, residential, service and agricultural demands) and used as input in the MESSAGE model. The following two demand scenarios are considered:

a. Energy Efficiency - where it is expected that already planned measures of energy efficiency and Nearly Zero Energy buildings are adopted. This is in line with Cyprus TSO's electricity demand forecast 2014-2023; this scenario reflects the impact of the new directives (Directive 2010/31/EU) on energy efficiency.

b. Extra Efficiency - which assumes a substantial decoupling of electricity demand and economic activity, especially as the levels of electricity consuming equipment in most economic sectors are approaching saturation, and adoption of aggressive policies on energy efficiency and Nearly Zero Energy buildings legislation.

Figure 2 illustrates how electricity demand by customer category is expected to evolve up to 2030 in both scenarios.

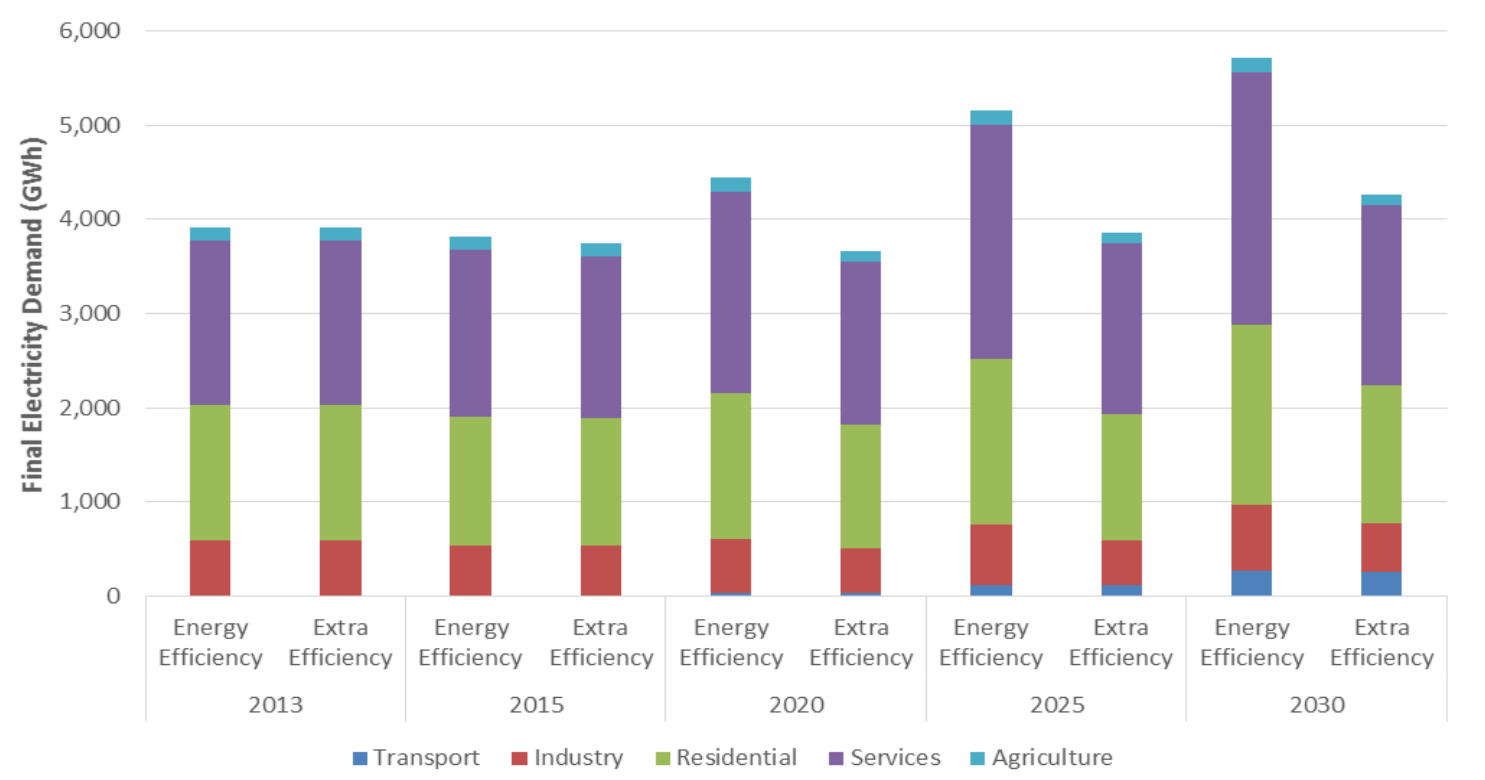

Figure 2. Final electricity demand projections by customer category in the Energy Efficiency scenario and Extra Efficiency scenarios [2].

Cyprus experiences hot summers and relatively mild winters. As such, electricity demand varies significantly throughout the year. In order to capture seasonal and daily load variability in as much detail as possible, a single year is broken down into a number of time-steps, based on recorded generation in 2012 [8]. Seven seasons have been identified in the present model (Figure 3). The length of each season varies according to the average demand of the period. For example, season 5, which starts on July $16^{\text {th }}$ and ends August $11^{\text {th }}$, (27 days) has the highest demand in the year (a peak of 997 $\mathrm{MW}$, a low of $468 \mathrm{MW}$ and an average demand of $732 \mathrm{MW}$ ), whereas season 3 starts on March $22^{\text {nd }}$, ends on June $5^{\text {th }}$ ( 76 days) and has the lowest demand in the year (a peak of $603 \mathrm{MW}$, a low of 298 $\mathrm{MW}$ and an average demand of $430 \mathrm{MW}$ ). Additionally, days in each season are broken down into 
weekdays and weekends, while each day is further divided into six (in the case of weekdays) or three (in the case of weekends) representative segments.

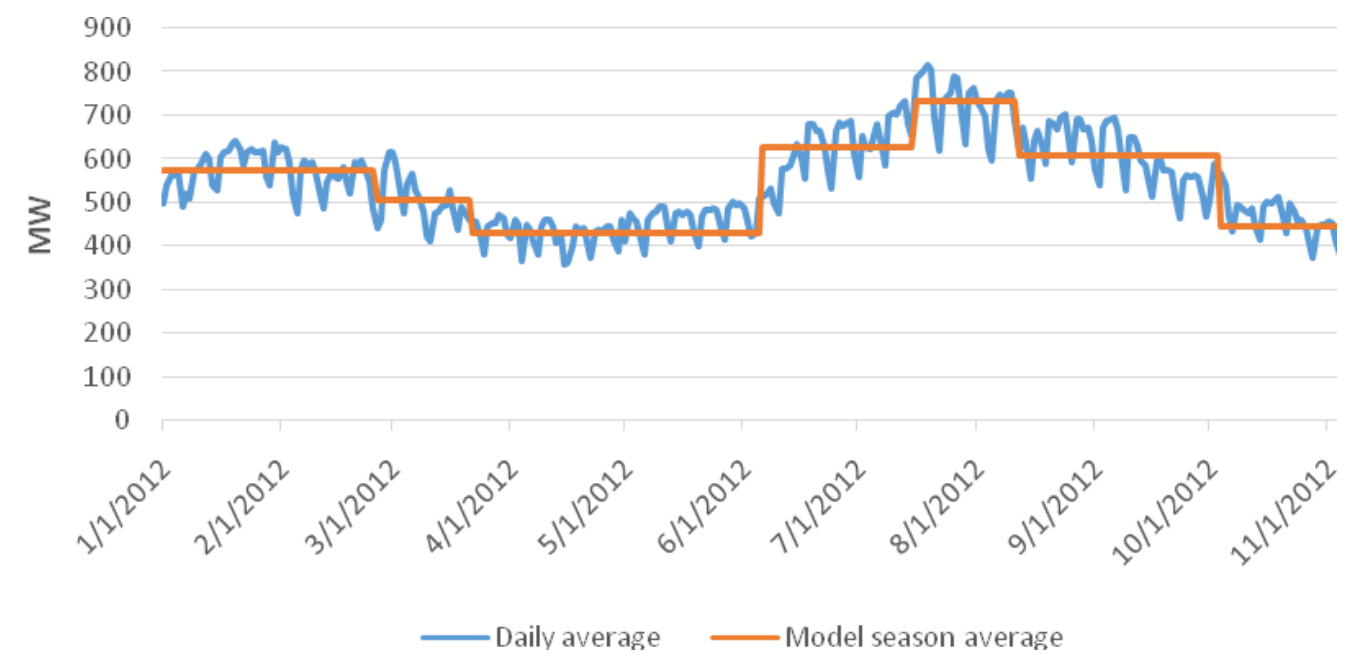

Figure 3. Seasonal variability in demand in 2012 and indication of the chosen 7 seasons

\subsubsection{Renewable energy targets}

As a European Union member state, Cyprus has to comply with the agreed renewable energy target of $13 \%$ in final energy consumption as defined by the Directive $2009 / 28 / E C$. This target has been disaggregated for the power sector up to 2020 [14], as shown in Table 2, but no target has been set beyond 2020. Nonetheless, an estimation of the aspirational renewable energy share for the period 2021-2030 has been provided by the government and has been used in the model as shown below. It is important to clarify that the 2030 target has not yet been revised following the recent agreement of a total contribution from renewables of $27 \%$ by 2030 across the European Union [15]. Further key modelling assumptions are presented in Appendices A-C.

Table 2. Minimum RES contribution to final electricity consumption

\begin{tabular}{ccccccccc}
\hline $\mathbf{2 0 1 3}$ & $\mathbf{2 0 1 4}$ & $\mathbf{2 0 1 5}$ & $\mathbf{2 0 1 6}$ & $\mathbf{2 0 1 7}$ & $\mathbf{2 0 1 8}$ & $\mathbf{2 0 1 9}$ & $\mathbf{2 0 2 0}$ & $\mathbf{2 0 2 1}$ \\
\hline $6.00 \%$ & $7.30 \%$ & $8.40 \%$ & $9.40 \%$ & $10.80 \%$ & $12.40 \%$ & $14.10 \%$ & $16.00 \%$ & $20.06 \%$ \\
$\mathbf{2 0 2 2}$ & $\mathbf{2 0 2 3}$ & $\mathbf{2 0 2 4}$ & $\mathbf{2 0 2 5}$ & $\mathbf{2 0 2 6}$ & $\mathbf{2 0 2 7}$ & $\mathbf{2 0 2 8}$ & $\mathbf{2 0 2 9}$ & $\mathbf{2 0 3 0}$ \\
$21.15 \%$ & $21.75 \%$ & $22.26 \%$ & $22.72 \%$ & $23.34 \%$ & $24.19 \%$ & $24.78 \%$ & $25.06 \%$ & $25.29 \%$ \\
\hline
\end{tabular}

\subsection{Scenario definitions}

As a first step in the analysis, a baseline of the existing power system is formulated to adequately represent the current status. The potential major infrastructure developments are then combined to define a number of scenarios, as shown in Table 3 and Figure 4.

Table 3. Attributes considered in each of the scenarios.

\begin{tabular}{cccccccc}
\hline Scenario & $\begin{array}{c}\text { Energy } \\
\text { Efficiency } \\
\text { Demand }\end{array}$ & $\begin{array}{c}\text { Extra } \\
\text { Efficiency } \\
\text { Demand }\end{array}$ & $\begin{array}{c}\text { Interim } \\
\text { Gas } \\
\text { Solution }\end{array}$ & $\begin{array}{c}\text { Electrical } \\
\text { Storage } \\
\text { Limitations }\end{array}$ & $\begin{array}{c}\text { Export } \\
\text { Liquefaction } \\
\text { terminal }\end{array}$ & $\begin{array}{c}\text { EuroAsia } \\
\text { Interconnector }\end{array}$ & $\begin{array}{c}\text { Domestic } \\
\text { gas for } \\
\text { power in } \\
\mathbf{2 0 2 3}\end{array}$ \\
\hline SC1 & $\sqrt{ }$ & & $\sqrt{ }$ & $\sqrt{ }$ & $\sqrt{ }$ & & $\sqrt{ }$ \\
SC2 & & $\sqrt{ }$ & & $\sqrt{ }$ & $\sqrt{ }$ & & $\sqrt{ }$ \\
SC3 & $\sqrt{ }$ & & $\sqrt{ }$ & $\sqrt{ }$ & $\sqrt{ }$ & $\sqrt{ }$ \\
SC4 & $\sqrt{ }$ & & $\sqrt{ }$ & & $\sqrt{ }$ & $\sqrt{ }$ \\
SC5 & $\sqrt{ }$ & & $\sqrt{ }$ & & $\sqrt{ }$ & $\sqrt{ }$ \\
SC6 & & & & & & & $\sqrt{ }$ \\
\hline
\end{tabular}


The significance of the above attributes for the analysis and their effect on the power supply system can be summarized as follows:

Energy Efficiency versus Extra Efficiency demands: As shown in Figure 2, Extra Efficiency demands follow a lower growth rate and remain below the 4 TWh level for the majority of the model period. As such, a lower demand in SC2 implies that investments in electricity generation will be reduced as compared to the other scenarios.

Interim Gas Solution: In all scenarios, with the exception of $\mathrm{SC} 1$, it is assumed that the negotiations regarding arrival of natural gas for the period 2016-2022 will be successful. In this case, all the units at the Vasilikos power plant will shift from heavy fuel oil and diesel to natural gas.

Electricity Storage and Interconnector: As explained in section 2.2.4.3, storage is assumed to become necessary beyond certain levels of wind and solar PV penetration. However, in scenarios where the EuroAsia Interconnector is implemented (i.e. SC5 and SC6), constraints on the maximum amount of solar PV and wind that can be deployed without storage are relaxed and the model is allowed to invest in higher capacities of these two renewable energy technologies, without the need to include electricity storage.

LNG Export Terminal: In case estimations about the volume of gas reserves are confirmed, it is possible that a liquefaction terminal will be built to allow export of liquefied natural gas (LNG). In such a case, a dedicated $200 \mathrm{MW}$ plant will be required to serve the electricity demand of the terminal. Therefore, the island will have to deploy more renewables in order to achieve the set renewable energy targets, as the electricity demand of the terminal will substantially increase the yearly electricity demand of the country.

Domestic gas: Based on the current energy plans, it is estimated that domestic gas will become available for the power sector in 2023. As such, it is assumed that no delay will occur in any of the scenarios.

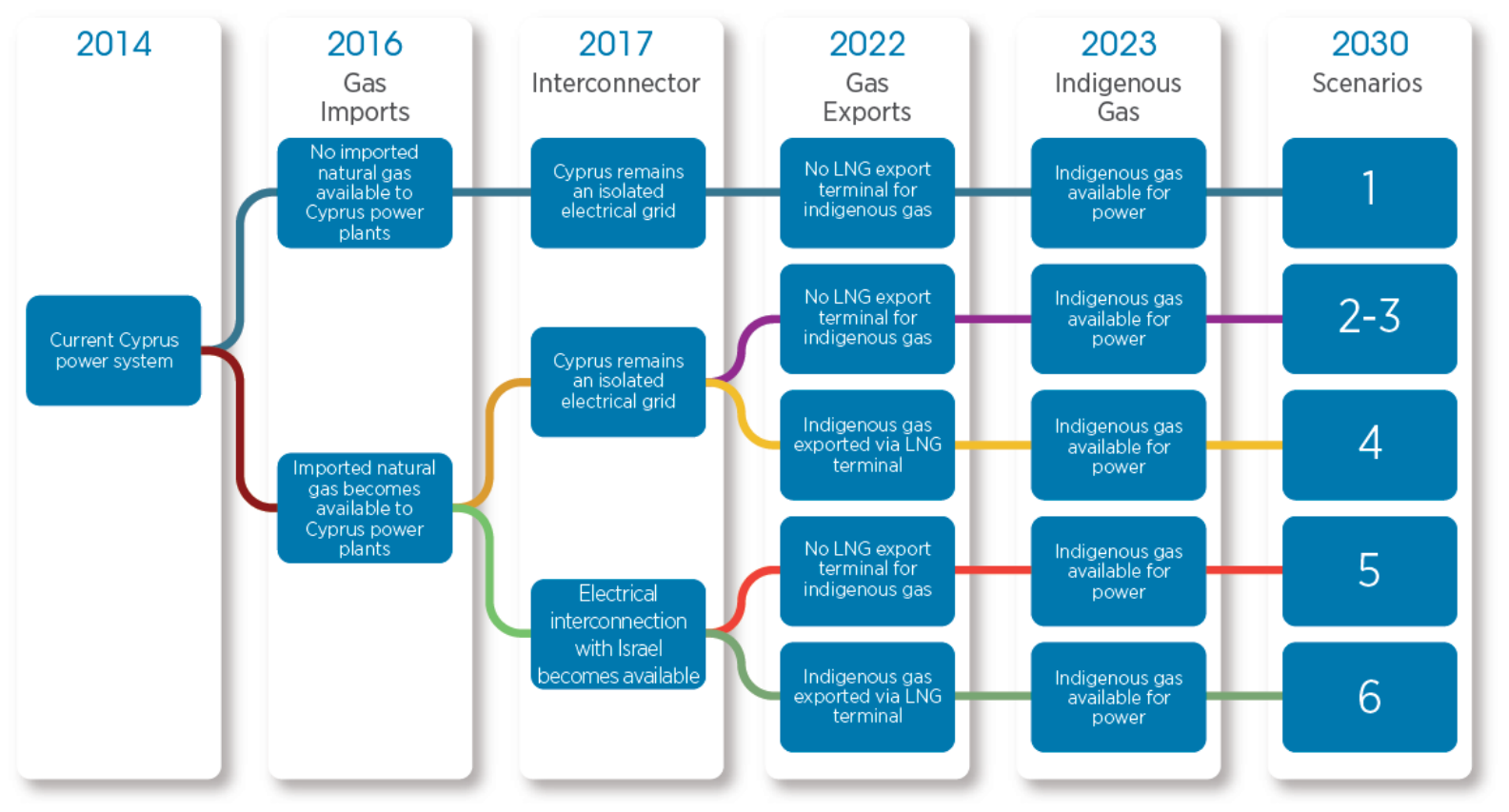

Figure 4. Definition of six scenarios for the evolution of Cyprus electricity system [2] 


\section{Results}

\subsection{Scenario analysis}

In SC1, where heavy fuel oil remains as the main fuel in the period 2013-2019, strict regulations in regards to industrial emissions come into effect in 2020, forcing a switch from HFO to diesel and low sulphur fuel oil. The situation shifts once again as domestic natural gas production begins in 2022 and is fully introduced for power generation in 2023; at this point all fossil-fired generation is based on natural gas. At the same time, generation from renewable energy sources steadily increases primarily due to their increased cost-competitiveness as investment costs reduce over time. Due to the increasing demand and sizable investments in renewable energy technologies, which have a lower capacity factor that fossil-fuel plants, the installed capacity of the island increases gradually from 1.68 GW in 2013 to $2 \mathrm{GW}$ in 2030 (Error! Reference source not found.). It is important to note that solar PV deployment occurs much faster than in any other scenario, exceeding $400 \mathrm{MW}$ by 2020; this is the only scenario without implementation of an interim gas solution.

Table 4. Total installed capacity evolution in the six scenarios (MW)

\begin{tabular}{|c|c|c|c|c|c|c|c|}
\hline & & Fossils & Wind & PV & CSP & Biomass & Total \\
\hline \multirow[t]{4}{*}{ SC1 } & 2015 & 1,509 & 147 & 125 & 0 & 20 & 1,801 \\
\hline & 2020 & 1,389 & 213 & 427 & 50 & 28 & 2,108 \\
\hline & 2025 & 1,075 & 213 & 460 & 50 & 28 & 1,826 \\
\hline & 2030 & 1,113 & 251 & $559 *$ & 50 & 28 & 2,001 \\
\hline \multirow[t]{4}{*}{ SC2 } & 2015 & 1,509 & 147 & 85 & 0 & 17 & 1,758 \\
\hline & 2020 & 1,389 & 175 & 157 & 50 & 17 & 1,789 \\
\hline & 2025 & 1,075 & 175 & 252 & 50 & 17 & 1,569 \\
\hline & 2030 & 943 & 175 & 468 & 50 & 17 & 1,653 \\
\hline \multirow[t]{4}{*}{ SC3 } & 2015 & 1,509 & 147 & 98 & 0 & 19 & 1,773 \\
\hline & 2020 & 1,389 & 175 & 200 & 50 & 19 & 1,834 \\
\hline & 2025 & 1,079 & 175 & 463 & 50 & 24 & 1,792 \\
\hline & 2030 & 1,113 & 251 & $559^{*}$ & 50 & 28 & 2,001 \\
\hline \multirow[t]{4}{*}{ SC4 } & 2015 & 1,509 & 147 & 77 & 0 & 19 & 1,751 \\
\hline & 2020 & 1,389 & 175 & 210 & 50 & 20 & 1,844 \\
\hline & 2025 & 1,075 & 248 & 571 & 50 & 40 & 1,983 \\
\hline & 2030 & 976 & 275 & $688^{* *}$ & 83 & 40 & 2,062 \\
\hline \multirow[t]{4}{*}{ SC5 } & 2015 & 1,509 & 147 & 98 & 0 & 19 & 1,773 \\
\hline & 2020 & 1,389 & 175 & 200 & 50 & 19 & 1,834 \\
\hline & 2025 & 1,075 & 175 & 568 & 50 & 22 & 1,890 \\
\hline & 2030 & 943 & 372 & 968 & 50 & 24 & 2,356 \\
\hline \multirow[t]{4}{*}{ SC6 } & 2015 & 1,509 & 147 & 77 & 0 & 19 & 1,751 \\
\hline & 2020 & 1,389 & 175 & 198 & 50 & 20 & 1,833 \\
\hline & 2025 & 1,075 & 277 & 598 & 50 & 40 & 2,039 \\
\hline & 2030 & 943 & 352 & 998 & 50 & 40 & 2,382 \\
\hline
\end{tabular}

Final electricity demand is a key driver for the level of production and mix of technologies chosen by the model. When a lower demand is used in scenario SC2, the results change considerably. Even though in this scenario the interim gas solution is assumed to materialize, conclusions can be made 
through a comparison with SC1 for the latter half of the assessment period (i.e. 2023-2030). In the extra-efficiency demand scenario, the total volume of electricity generated is considerably lower (Figure 5), which is also reflected in the total installed capacity. Total installed capacity by 2030 is lower by about $350 \mathrm{MW}$ in SC2 as compared to scenario SC1 (Error! Reference source not found.). Even though this scenario implies reduced need for investment in the power sector, benefits should be evaluated against the costs of achieving a lower electricity demand (Figure 5).

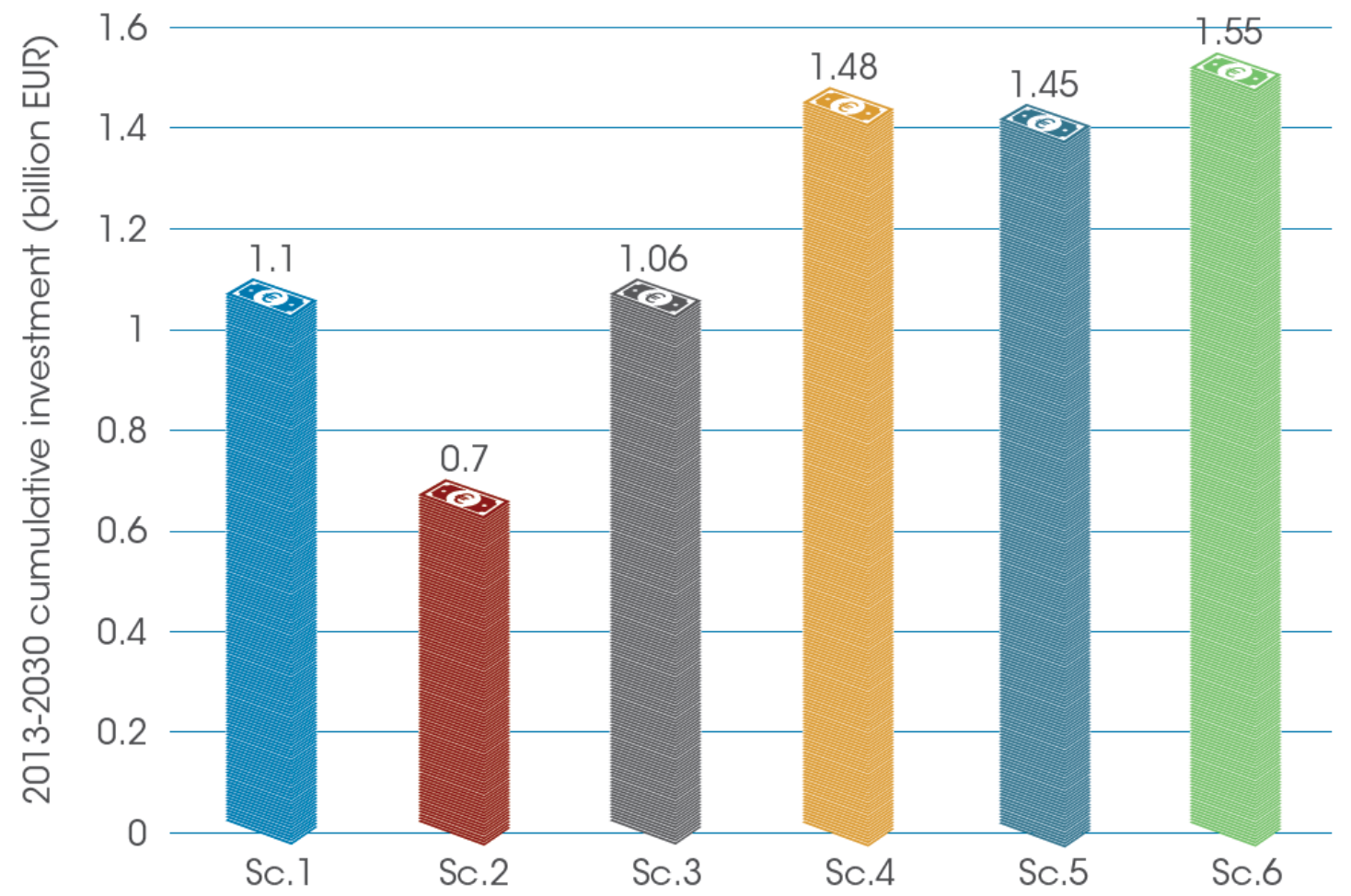

Figure 5 - Investment needs ${ }^{3}$ for power generation assets in different scenarios. To be noted the substantially lower needs in scenario 2, where the extra efficiency demand scenario is used (Source: IRENA, 2015 [2]

While fossil-fuelled generation reaches $4,550 \mathrm{GWh}$ in scenario SC1 in 2030, in scenario SC2 this reduces to $3,200 \mathrm{GWh}$. At the same time, generation from renewable energy sources drops slightly from $1,570 \mathrm{GWh}$ to $1,260 \mathrm{GWh}$ for the same year.

In scenario SC3 the generation mix and total installed capacity are identical to SC1 by the end of the model horizon (i.e. 2030). However, in SC3 investments in renewables generally occur later in the model period. For instance, in 2020 capacities of solar PV and wind amount to 200 and $175 \mathrm{MW}$ respectively in SC3; the corresponding values for the same year are 427 and $213 \mathrm{MW}$ in SC1. This difference can be attributed to the fact that imports of gas through the interim gas solution in SC3 allow generation at lower costs than currently observed, which will reduce the urgency of investing in $\mathrm{RE}$, without however changing the long term need for shifting Cyprus electricity system towards RE.

In case a liquefaction terminal is developed on the island (SC4), additional installations of renewables will be required for the island to meet its aspirational renewable energy targets. This is apparent in the results of this scenario, where solar PV capacity reaches $688 \mathrm{MW}$ by 2030. In order for the capacity of PV to reach such high levels, capacities of $138 \mathrm{MW}$ are served by storage at the distribution level (Li-Ion batteries). At the same time, in this scenario an additional $33 \mathrm{MW}$ of CSP with storage are installed, further to the committed $50 \mathrm{MW}$. Similarly, capacity of biomass-fired facilities reaches 40

\footnotetext{
${ }^{3}$ Billion refers to the short scale of numbering - i.e. $10^{9}$.
} 
MW. It should be noted that it would not be surprising if Cyprus requests that the $200 \mathrm{MW}$ gas-fired unit at the LNG terminal be exempted from the country's own energy consumption. Since the LNG terminal may potentially serve the interests of other European Union member states, such an argument may be supported.

Results from SC5 provide interesting insights. In this scenario Cyprus becomes interconnected with Greece and Israel, and as such limitations on variable renewables' capacity are removed and a greater flexibility is given to the model. In this case, installed capacities of PV and wind reach 968 and $372 \mathrm{MW}$ respectively by 2030 . As a result, the share of renewable energy generation exceeds $40 \%$ by 2030 .

Similar to SC5, generation from renewables in a scenario with both an interconnector and an LNG terminal (SC6) exceeds aspirational renewable energy targets in 2030, as within this timeframe, the share manages to reach $33 \%$. Contribution from renewables to the generation mix is comparable to SC4 until 2024 (both scenarios consider development of an LNG terminal), but capacity additions of renewables without storage continue to occur in SC6, due to the assumed flexibility offered by the interconnector. As such, wind capacity reaches $352 \mathrm{MW}$ while solar PV capacity is $998 \mathrm{MW}$ by 2030. As this study does not include a detailed engineering feasibility of how this capacity should be integrated in the grid, the key message is that - unless major technical limitations remain in Cyprus grid - an interconnector would allow for large scale deployment of RE as part of a least-cost power generation mix. Some additional cost might be incurred to deploy measures to integrate such large capacity of variable renewables. However, the cost of such measures will not alter the key message that renewables will play a major role in reducing the cost of electricity generation and in ensuring compliance with global and local emissions limits.

As mentioned above and shown in Figure 5, solar PV at the transmission level is the most cost-efficient renewable technology for Cyprus. Solar PV is the dominant renewable energy technology in all scenarios, with limited contributions from CSP, wind and biomass-fired facilities. Investments in solar PV are quite high in all scenarios; and remarkably high in scenarios SC5 and SC6, which assume deployment of the EuroAsia Interconnector.

In the case of wind, no expansion occurs in scenario SC2 beyond the committed level of $175 \mathrm{MW}$. In SC1 and SC3 wind capacity amounts to $251 \mathrm{MW}$ in 2030. In SC5 and SC6 wind capacity in 2030 reaches 372 and $352 \mathrm{MW}$ respectively. Finally, in SC4 wind capacity reaches $275 \mathrm{MW}$ by 2030, which is the deployment limit without storage for that year.

In the case of biomass, minimal new installations occur in scenario $\mathrm{SC2}$, while capacity increases by 18 $\mathrm{MW}$ in the higher demand scenarios with and without interim gas solution (SC1 and SC3), $30 \mathrm{MW}$ in the scenarios with the development of an LNG facility (SC4 and SC6) and $14 \mathrm{MW}$ in the scenario with only an interconnector developed (SC5). Biomass-fired facilities are allowed to add a total maximum capacity of $30 \mathrm{MW}$, which means that with the exception of scenarios SC4 and SC6 this option is not as cost-competitive, based on the assumptions adopted in this study.

Based on scenario results from SC5 and SC6, it could be argued that benefits from a grid interconnection are threefold. First of all, Cyprus gains access to separate power supply systems, from which it can import during periods of peak demand to avoid expensive generation options (as in 2020 - Figure 6) or to cover periodic shortages in supply. Secondly, a higher share of variable renewables can be deployed with lower requirements for storage, as variations in renewable energy generation can possibly be balanced via the grid interconnection. At the same time, exports of electricity can occur (although not explicitly modelled in this analysis), thus preventing curtailment. Finally, by replacing gas-fired generation with renewables, a larger volume of indigenous gas is available for 
exports. It can thus be seen why the European Union gives such importance in projects of common interest that can expand grid interconnector networks in numerous member states [1].
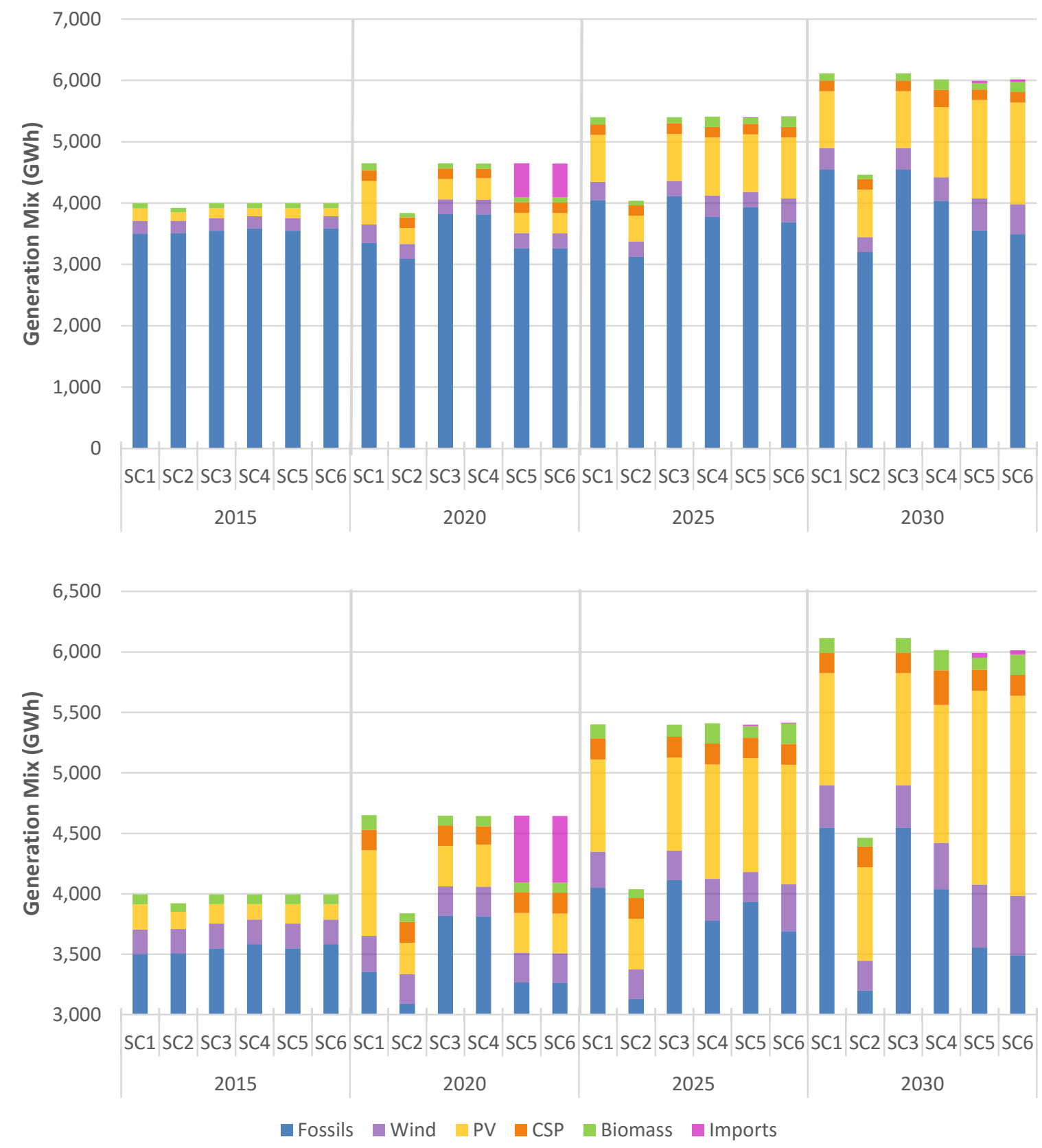

Figure 6. Evolution of generation mix in the six scenarios. The bottom chart provides a more focused overview of differences in renewable energy contribution in different scenarios (self-generation for the LNG terminal is excluded)

Despite the fact that the technical feasibility of these high level of variable renewables in the case of interconnection should be further examined in a separate grid analysis, examples of countries with good level of interconnection reaching high shares of variable renewables exist in Europe (e.g. Denmark). The case of Ireland is particularly relevant, being an island as well, and having followed a similar assessment for its large-scale deployment of variable RETs [16]. At first, a long-term energy assessment was carried out, similar to the present study, and was then followed by a resource assessment, identification of potential RE project locations, a dispatching study, a grid stability study and finally a cost-benefit analysis. This approach can be regarded as a best practice for smooth integration of high shares of variable renewables in an island power system. 
Regardless of the benefits, two highly significant issues are associated to the electrical interconnection. The first relates to system reliability in the case of an interruption of supply from the cable. The second relates to sovereignty issues, where the Cyprus economy may become dependent on electricity supply from a separate system. This should be looked at in terms of both reliability (operational reserves) and security (capacity reserve). These issues are important and are worth keeping into consideration, although they are outside the scope of this study.

\subsubsection{Cost-Competitiveness of Renewable Energy Technologies}

In order to assess the cost-competitiveness of renewable energy technologies, a comparison of the renewable energy share in each scenario is provided (Error! Reference source not found.). As described in section 2.2.4, a minimum renewable energy share is defined in the analysis. However, results from the scenarios suggest that renewable energy technologies gain competitiveness when compared to fossil-fired generation, as a result of increasing fuel prices and decreasing RET investment cost.

Table 5. Share of renewable energy generation in each scenario as compared to the renewable energy targets (underlined values exceed the predefined renewable energy target)

\begin{tabular}{|c|c|c|c|c|c|c|c|c|}
\hline & SC1 & SC2 & SC3 & SC4 & SC5 & SC6 & RE target & \multirow{9}{*}{$\begin{array}{l}\frac{\delta}{3} \\
\frac{3}{0} \\
\frac{c}{w} \\
\frac{0}{2}\end{array}$} \\
\hline 2013 & $\underline{6.5 \%}$ & $\underline{6.5 \%}$ & $\underline{6.5 \%}$ & $\underline{6.5 \%}$ & $\underline{6.5 \%}$ & $\underline{6.5 \%}$ & $6.0 \%$ & \\
\hline 2014 & $\underline{7.5 \%}$ & $7.5 \%$ & $\underline{7.5 \%}$ & $\underline{7.5 \%}$ & $7.5 \%$ & $\underline{7.5 \%}$ & $7.3 \%$ & \\
\hline 2015 & $12.4 \%$ & $10.6 \%$ & $11.2 \%$ & $10.3 \%$ & $11.2 \%$ & $10.3 \%$ & $8.4 \%$ & \\
\hline 2016 & $16.5 \%$ & $11.5 \%$ & $\underline{11.5 \%}$ & $10.9 \%$ & $11.5 \%$ & $10.9 \%$ & $9.4 \%$ & \\
\hline 2017 & $\underline{21.6 \%}$ & $12.2 \%$ & $11.8 \%$ & $\underline{11.4 \%}$ & $11.8 \%$ & $\underline{11.4 \%}$ & $10.8 \%$ & \\
\hline 2018 & $\underline{28.0 \%}$ & $\underline{18.4 \%}$ & $\underline{16.8 \%}$ & $16.6 \%$ & $\underline{16.8 \%}$ & $\underline{16.6 \%}$ & $12.4 \%$ & \\
\hline 2019 & $\underline{27.9 \%}$ & $\underline{18.9 \%}$ & $\underline{16.8 \%}$ & $\underline{16.8 \%}$ & $\underline{16.8 \%}$ & $16.8 \%$ & $14.1 \%$ & \\
\hline 2020 & $\underline{27.9 \%}$ & $\underline{19.5 \%}$ & $\underline{17.8 \%}$ & $17.9 \%$ & $\underline{17.8 \%}$ & $17.9 \%$ & $16.0 \%$ & \\
\hline 2021 & $27.5 \%$ & $20.1 \%$ & $20.1 \%$ & $20.1 \%$ & $20.1 \%$ & $20.1 \%$ & $20.1 \%$ & \\
\hline 2022 & $27.0 \%$ & $21.8 \%$ & $21.2 \%$ & $21.2 \%$ & $21.2 \%$ & $21.2 \%$ & $21.2 \%$ & \\
\hline 2023 & $\underline{26.0 \%}$ & $21.8 \%$ & $21.8 \%$ & $\underline{22.7 \%}$ & $\underline{22.9 \%}$ & $\underline{22.7 \%}$ & $21.8 \%$ & \\
\hline 2024 & $\underline{25.4 \%}$ & $22.3 \%$ & $\underline{22.9 \%}$ & $\underline{23.2 \%}$ & $\underline{24.8 \%}$ & $\underline{23.3 \%}$ & $22.3 \%$ & 点 \\
\hline 2025 & $\underline{25.0 \%}$ & $22.7 \%$ & $\underline{23.8 \%}$ & $23.7 \%$ & $\underline{26.9 \%}$ & $24.9 \%$ & $22.7 \%$ & \\
\hline 2026 & $\underline{25.9 \%}$ & $23.3 \%$ & $\underline{24.6 \%}$ & $\underline{24.3 \%}$ & $\underline{28.9 \%}$ & $\underline{26.4 \%}$ & $23.3 \%$ & \\
\hline 2027 & $\underline{25.7 \%}$ & $24.2 \%$ & $\underline{24.5 \%}$ & $\underline{25.2 \%}$ & $\underline{30.7 \%}$ & $\underline{27.9 \%}$ & $24.2 \%$ & $\stackrel{\mathrm{D}}{\underline{\partial}}$ \\
\hline 2028 & $25.5 \%$ & $\underline{26.1 \%}$ & $24.8 \%$ & $\underline{25.9 \%}$ & $\underline{32.4 \%}$ & $\underline{29.3 \%}$ & $24.8 \%$ & \\
\hline 2029 & $\underline{25.3 \%}$ & $\underline{28.6 \%}$ & $25.1 \%$ & $\underline{26.1 \%}$ & $\underline{36.4 \%}$ & $\underline{30.6 \%}$ & $25.1 \%$ & \\
\hline 2030 & $\underline{25.6 \%}$ & $28.3 \%$ & $\underline{25.6 \%}$ & $\underline{26.4 \%}$ & $\underline{40.1 \%}$ & $\underline{33.2 \%}$ & $25.3 \%$ & \\
\hline
\end{tabular}

The share of renewable energy generation achieves and exceeds the compulsory $16 \%$ target by 2020 in all scenarios. To an extent this can be attributed to committed projects, such as the $50 \mathrm{MW}$ CSP facility to be commissioned at the end of 2017. Similarly, the Net Metering scheme encourages an annual installation of $15 \mathrm{MW}$ distributed PV at households and public buildings until 2020. In the years 2021-2022 some of the scenarios just manage to achieve the aspirational targets. During this period, the interim gas solution is still ongoing, with the exception of SC1, where diesel and low-S fuel oil are the primary fuel sources. 


\subsection{Sensitivity analysis}

\subsubsection{Price of Gas for Power Generation}

It is anticipated that the fuel shift from heavy fuel oil and diesel to natural gas for power generation will lead to a lower generation cost. However, this is linked directly to the price at which domestic consumers (e.g. Electricity Authority of Cyprus for its power plants) will purchase extracted natural gas, and this is primarily a political decision, which is yet to be made. In order to assess how gas price affects the generation mix of the country, a sensitivity analysis is conducted. At first, scenario SC3 is used as a basis and the price of domestic natural gas is adjusted within a range of prices, from a low netback price (EUR 4.5/Mbtu) to a projected market price, as quoted in section 2.2.3 (approximately EUR 9/Mbtu).

The model does not appear to be sensitive to gas price reductions in such a case, which can be attributed to the following reasons. First of all, the aspirational targets for RE generation during 20212030, do not allow gas-fired generation to exceed a threshold, even when the price is significantly lower. Secondly, large capacity additions occur up to 2023 in RE generation and as such contribution from renewable technology options remains at high levels throughout the model period. Thirdly, when a market price is used, in the absence of an interconnector, renewables are limited by technical constraints relating to grid stability (Appendix A.3). As renewables reach these limits, requirements for storage reduce cost-competitiveness of RE generation. Thus, another round of sensitivity is conducted by taking scenario SC5, thus removing capacity limits on wind and solar PV, and altering the price of indigenous gas.

As shown in Table 6, generation mix becomes more sensitive to the indigenous gas price in case an interconnection occurs. Since in this case a greater flexibility is assumed and storage constraints are lifted in the model, renewable energy technologies are more cost-competitive when the price of gas is high. Specifically, as discussed above, renewables reach a share in generation of $40 \%$ by 2030 when a market price is used. If the price of indigenous gas is reduced slightly to EUR 8.3 from EUR 9/Mbtu, assuming moderate implicit gas subsidies due to a lost opportunity for exporting the gas at higher price, renewable energy share reaches $30 \%$ by 2030 . This means that renewables still manage to exceed the aspirational target of $25 \%$ by 2030 . However, once the price of indigenous gas decreases to EUR 7.5/Mbtu, generation share of renewables is limited to the aspirational targets. This suggests that indigenous gas prices below EUR 8.3/Mbtu can affect the deployment of renewables.

Table 6. Share of gas-fired and RE-based generation as a function of gas price in SC5

\begin{tabular}{ccccccccc}
\hline \multicolumn{1}{c}{ EUR 4.5/Mbtu } & \multicolumn{2}{c}{ EUR 7.5/Mbtu } & \multicolumn{2}{c}{ EUR 8.3/Mbtu } & \multicolumn{2}{c}{ Market price } \\
\hline & Gas & Renewables & Gas & Renewables & Gas & Renewables & Gas & Renewables \\
\hline $\mathbf{2 0 2 3}$ & $78 \%$ & $22 \%$ & $78 \%$ & $22 \%$ & $78 \%$ & $22 \%$ & $77 \%$ & $23 \%$ \\
\hline $\mathbf{2 0 2 4}$ & $78 \%$ & $22 \%$ & $78 \%$ & $22 \%$ & $78 \%$ & $22 \%$ & $75 \%$ & $25 \%$ \\
$\mathbf{2 0 2 5}$ & $77 \%$ & $22 \%$ & $77 \%$ & $23 \%$ & $77 \%$ & $23 \%$ & $73 \%$ & $27 \%$ \\
\hline $\mathbf{2 0 2 6}$ & $77 \%$ & $23 \%$ & $77 \%$ & $23 \%$ & $76 \%$ & $24 \%$ & $71 \%$ & $29 \%$ \\
$\mathbf{2 0 2 7}$ & $75 \%$ & $24 \%$ & $76 \%$ & $24 \%$ & $75 \%$ & $25 \%$ & $69 \%$ & $31 \%$ \\
\hline $\mathbf{2 0 2 8}$ & $75 \%$ & $25 \%$ & $75 \%$ & $25 \%$ & $73 \%$ & $27 \%$ & $67 \%$ & $32 \%$ \\
$\mathbf{2 0 2 9}$ & $74 \%$ & $25 \%$ & $74 \%$ & $25 \%$ & $71 \%$ & $28 \%$ & $63 \%$ & $36 \%$ \\
\hline $\mathbf{2 0 3 0}$ & $74 \%$ & $25 \%$ & $74 \%$ & $25 \%$ & $69 \%$ & $30 \%$ & $59 \%$ & $40 \%$ \\
\hline
\end{tabular}

Comment: $1 \%$ Difference in some years relates to the import of electricity 


\subsubsection{Renewable Energy Targets}

In order to assess whether the renewable energy targets in the period 2021-2030 are the main driving force for investments in renewables, a simple sensitivity analysis has been conducted. The results above indicate that in SC3 the share of renewable energy is very close to that of the minimum target. Therefore, this scenario is altered so that renewable energy targets remain at the compulsory levels as set by the European Union for 2020; $16 \%$ of generation for the period 2021-2030. As shown in Figure 7 , differences in generation mix are extremely minute.
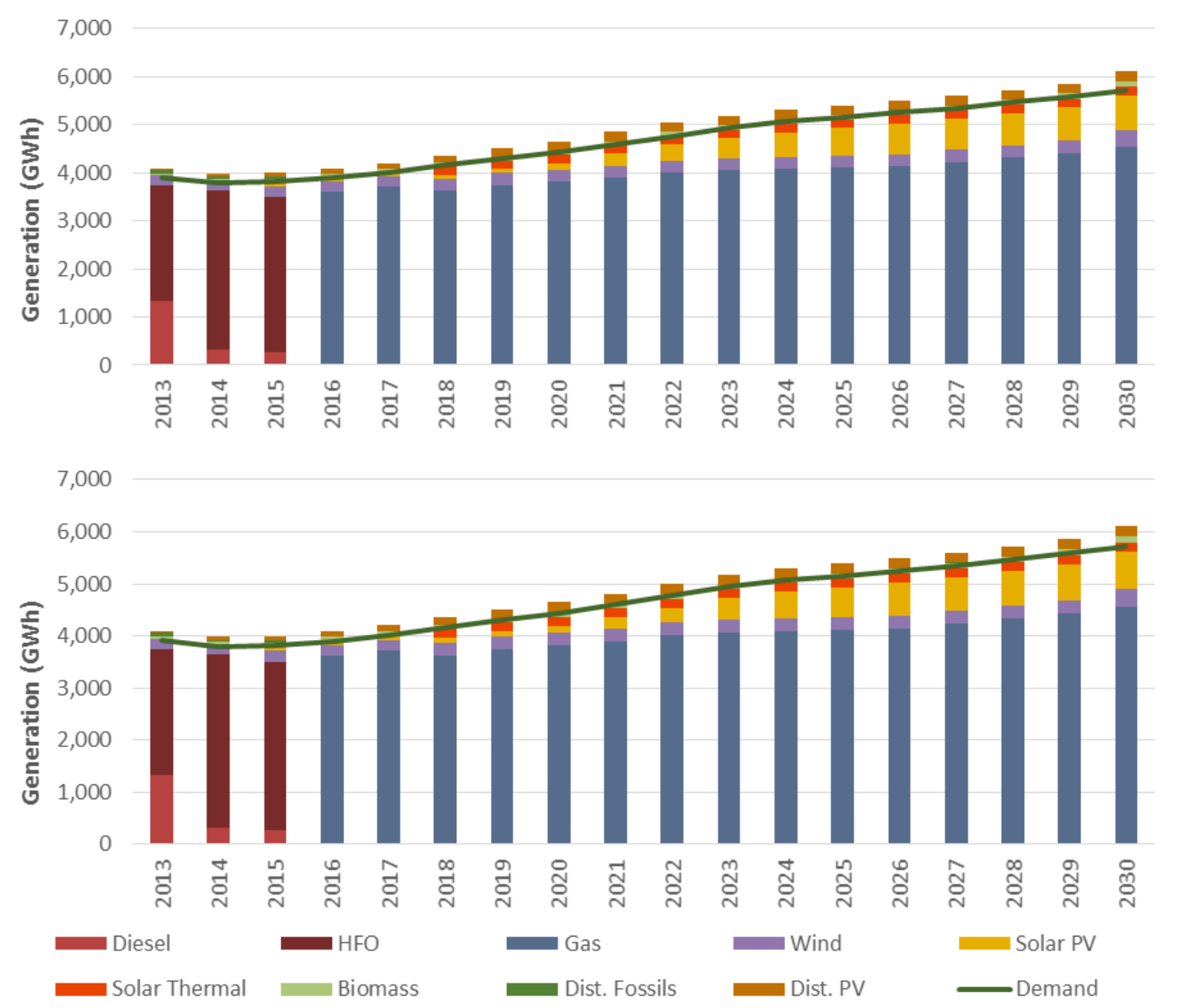

Figure 7. Generation mix in SC3 with (top) and without (bottom) aspirational renewable energy targets

Cost differences between the two cases are minimal. Investments are higher, while fuel and $\mathrm{CO}_{2}$ costs are lower in the case with enforced aspirational renewable energy targets, which lead to a marginal total difference of EUR 4 million over the entire model period. This indicates that, based on the assumptions on costs, performance and technical constraints, and assuming proper market conditions are in place, minimal additional investment requirements are needed for the island to achieve its aspirational renewable energy targets, only in one scenario. In all other scenarios, these targets are exceeded based on a purely economic argument.

Even though in previous studies it has been argued that renewable energy technologies would lead to an unavoidable increase in the cost of electricity [4], results from the sensitivity analysis shown here indicate otherwise. This difference can be attributed to the high price of oil experienced in recent years, along with the significant reduction in investment cost of certain technologies; particularly of solar PV. 


\subsubsection{Low oil price}

Following the recent significant decline in international crude oil prices, concerns are being raised as to the cost-competitiveness of renewable energy technologies. In addition to the existing sensitivity analysis presented above and in the relevant report [2], we conduct a short sensitivity analysis on how the generation mix may look like in the medium-term (2015-2020), in case oil prices remain at levels lower than those previously projected. Table 7 below shows the price difference assumption that is investigated in scenarios $\mathrm{SC} 1$ and $\mathrm{SC} 3$, so as to investigate effects on renewable energy deployment and the competitiveness of the interim gas solution respectively.

Table 7. Crude oil low price assumption as compared to IEA projections for 2015-2020.

\begin{tabular}{|c|c|c|c|c|c|c|c|}
\hline & & 2015 & 2016 & 2017 & 2018 & 2019 & 2020 \\
\hline \multirow[t]{2}{*}{ US \$/barrel } & IEA projections [17] & 110.5 & 111 & 111.5 & 112 & 112.5 & 113 \\
\hline & Assumed low oil price & 60 & 65 & 75 & 85 & 95 & 113 \\
\hline
\end{tabular}

As indicated by Figure 8, when a low oil price assumption is used the deployment schedule of solar PV is altered. In SC1 it is assumed that the interim gas solution negotiations are not successful and the island remains dependent on oil-fired generation; price of oil in this case is based on IEA projections. As such, generation cost from the fossil-fired power plants is high, which triggers a faster rate of investment in transmission-connected solar PV. However, when a low-oil price is assumed, the costcompetitiveness of solar PV is affected significantly. Even though the share of renewables in the generation mix remains above the predefined target, investments are delayed. For instance, in 2018 transmission-connected solar PV contributes to only $5.7 \%$ compared to $11.8 \%$ when the original oil price assumption from the IEA [19] are used.

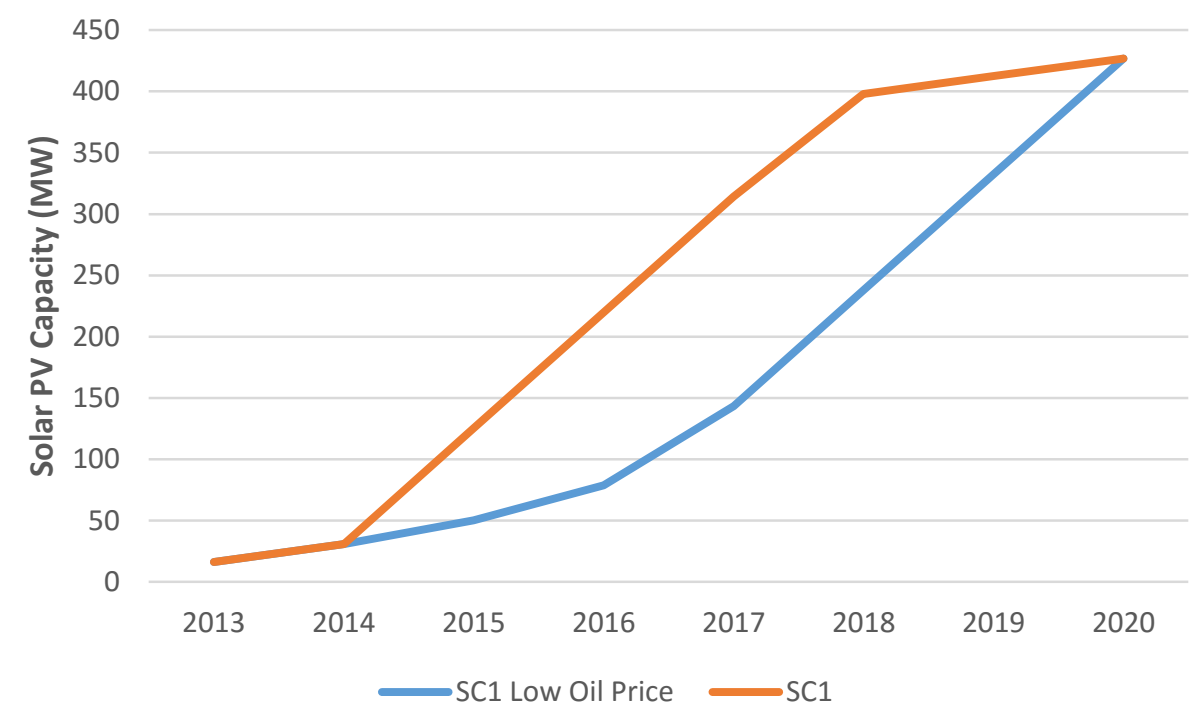

Figure 8. Solar PV capacity evolution with and without a low oil price assumption.

In the case of SC3, which assumes a successful negotiation for the interim gas solution, deployment of PV remains the same even with a low oil price assumption. Nonetheless, the financial viability of the interim gas solution is questioned in an environment of prolonged low oil prices. As Error! Reference source not found. indicates, if crude oil prices remain at low levels, the economic sense of a proposed early fuel shift by means of gas imports may have to be reevaluated. This is a clear indication of the dilemmas faced by energy planners whose systems are highly import dependent and 
thus vulnerable to fuel price fluctuations. Of course, this aspect is beyond the scope of this study and requires a far more detailed analysis, which cannot be offered explicitly within the context of the present analysis.

Table 8. Share of heavy fuel oil versus gas-fired generation during 2016-2020.

\begin{tabular}{|l|c|c|c|c|}
\hline & \multicolumn{2}{|c|}{ SC3 } & \multicolumn{2}{c|}{ SC3 Low Oil Price } \\
\hline $\mathbf{2 0 1 6}$ & Heavy fuel oil & Gas & Heavy fuel oil & Gas \\
\hline $\mathbf{2 0 1 7}$ & $0 \%$ & $88 \%$ & $82 \%$ & $0 \%$ \\
\hline $\mathbf{2 0 1 8}$ & $0 \%$ & $88 \%$ & $80 \%$ & $9 \%$ \\
\hline $\mathbf{2 0 1 9}$ & $0 \%$ & $83 \%$ & $20 \%$ & $63 \%$ \\
\hline $\mathbf{2 0 2 0}$ & $0 \%$ & $83 \%$ & $11 \%$ & $73 \%$ \\
\hline
\end{tabular}

\section{Discussion}

This study is neither about predicting the evolution of the electricity system of Cyprus nor about prescribing preferences for its development. Rather, it attempts to provide insights on the risk and benefits of different scenarios of electricity system development. A clear message from the analysis is that renewable energy technologies can contribute to a future reduction in the generation cost of the system (see Figure 9).

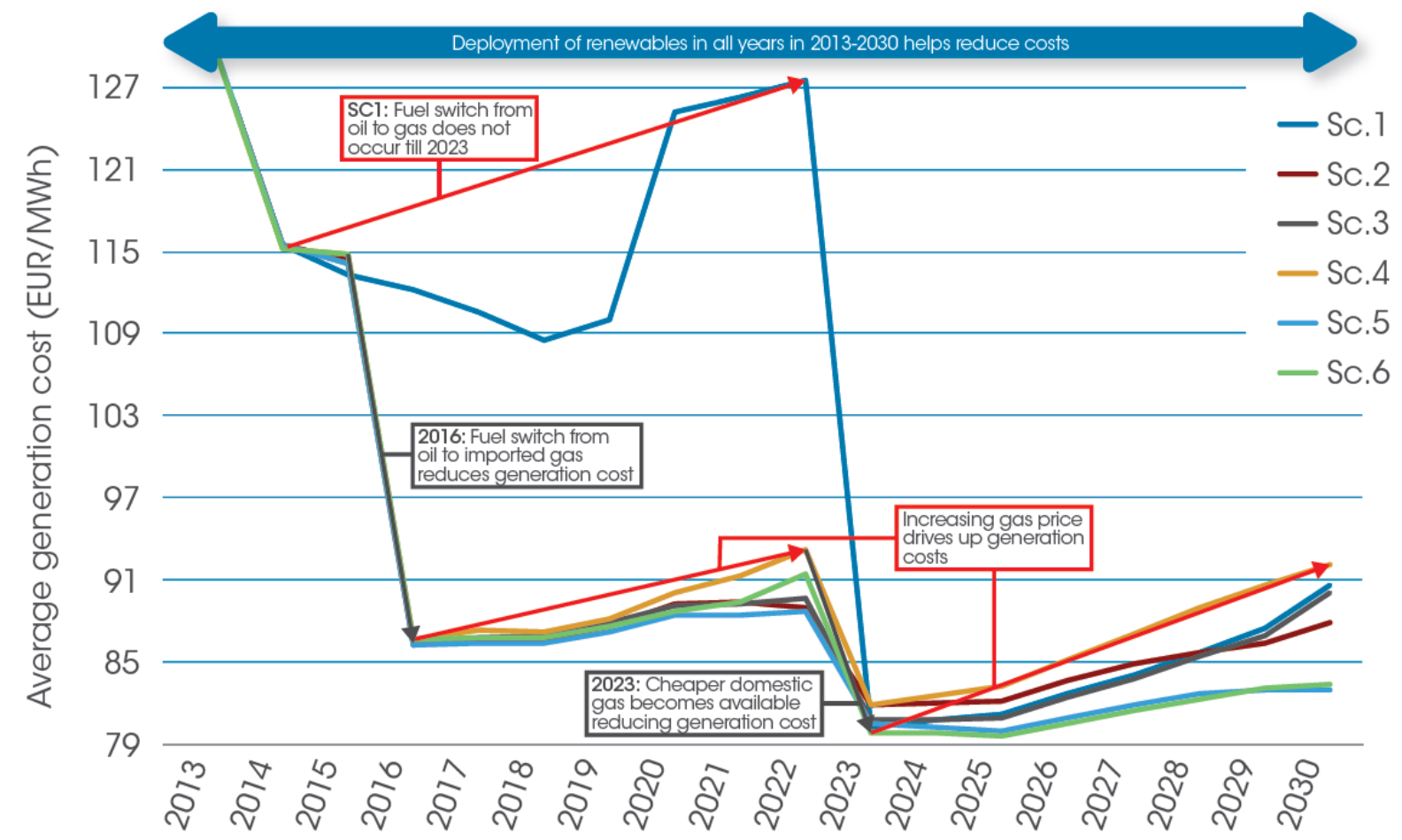

Figure 9 - Evolution of power generation cost in Cyprus under different scenarios [2]

Utility scale solar PV is the most competitive option, but results from the analysis indicate that investments should occur immediately, as the most aggressive savings can be achieved before natural gas becomes available, when the main fuels that will be offset are diesel and fuel oil. This means that a framework needs to be set in place to accommodate smooth integration of high shares of variable renewables. First of all, supporting ancillary services, such as operating reserves or energy storage, are required to reduce risk of an imbalance in the system [18]. It is argued that variable renewable technologies introduce an indirect cost to the power supply system [19]. Nonetheless, improved forecasting methods and state-of-art technologies for provision of grid support services from variable 
renewables exist that reduce the need for ancillary services, thus achieving lower system costs; these are discussed in detail in the official IRENA roadmap for Cyprus [2].

Furthermore, regulatory reform is often needed to attract investors. A competitive electricity market that offers system flexibility is recognized as a prerequisite for accommodating distributed generation from a number of producers [20]. Such a market structure does not exist yet in Cyprus, despite the European Commission's recommendation that member states should implement all legislative measures towards the design of competitive energy markets [21]. An electricity market is expected to be established in 2016 for Cyprus. However, concerns remain as to how renewable energy technologies will be treated in such a market.

Energy decision makers in Cyprus face a number of short-term challenges - expanding and diversifying electricity generation are among the highest priority. Each of the options - natural gas (imported and/or domestic off-shore), wind, solar PV or continued use of oil products - has different implications for infrastructure development and carries different risks. For examples, low oil prices over extended time periods can undermine the financial viability of otherwise economically attractive natural gas; natural gas imports, although beneficial for the reduction of generation price, will also pose a limit to the share of RE that can be accepted, based on how the import contract will be designed (e.g. setting minimum amounts of gas that will be purchased under a take or pay contract).

Infrastructure investments have inherently long amortization periods. Investing in gas pipelines linking the island to off-shore fields or building regasification plants for LNG imports lacks economic rationale if only operated for just a few years or for limited volumes. It is important to note that, in spite of current temporary reduction in oil prices, deploying RE will reduce the inherent volatility of electricity generation cost in Cyprus, creating a more stable environment for consumers to plan and budget for their energy costs.

Aggressive efficiency measures can reduce the need for investments in generating capacities, but a comparison of the costs of these measures will have to be conducted separately. One aspect that needs further assessment is the technical feasibility of the results, as the threshold set for maximum penetration of variable renewables needs to be set by a dynamic stability analysis of Cyprus power grid. Similarly, the possible need for energy storage under each scenario has not been examined in depth from the operational and technical point of view and neither has grid stability. Both of these aspects will have to be determined through separate studies. Additionally, similar to the case of Ireland [16], identification of sites where large renewable energy projects can be deployed will be relevant in the future. Once the specific sites for large projects are defined, a separate assessment focusing on grid strengthening will prove valuable for efficient system planning. As part of the ongoing grid study, an assessment of the most cost effective manner to integrate large shares of variable RE technologies should be conducted. For instance, this could be achieved through grid strengthening, introduction of centralized or decentralized storage, implementation of smart grids, use of advanced control methods, improvements in forecasting techniques for variable renewables, investments in an interconnection or most likely a combination of these options.

\section{Conclusions}

The Republic of Cyprus is faced with important decisions that will define the long-term energy outlook of the island. Major investments in infrastructure are imminent, and expected to change the energy mix and improve security of supply for this import-dependent country. The scenario analyses show these investments lead to different levels of electricity generating costs and can achieve generation cost savings compared with the current generating mix. 
Deployment of renewable energy technologies is not only necessary for Cyprus to achieve its EU targets, but results suggest that renewable energy technology integration will also result in a reduction of power generation cost up to 2023 in all scenarios examined. In terms of generation technologies, utility scale solar PV connected is the most competitive renewable option, with large scale deployment expected in all scenarios. Aggressive deployment in the model starts in 2015 , calling for immediate action by policy makers.

\section{Acknowledgments}

The authors wish to thank all the partners for their continued support, involvement and guidance during the course of this study, and especially Mr. George Partasides and Mr. losif Spyrides (MECIT), Dr. Constantinos Rouvas (EAC) and Dr. Constantinos Varnava (Cyprus TSO). 


\section{References}

[1] European Commission, "Projects of common interest - Electricity and Smart Grids," Oct-2014. [Online]. Available:

http://ec.europa.eu/energy/sites/ener/files/documents/2014_pcielec_smart_grid_cef.pdf. [Accessed: 11-Nov-2014].

[2] IRENA, "Renewable Energy Roadmap for the Republic of Cyprus," Abu Dhabi, 2015.

[3] Eurostat, "Electricity and natural gas price statistics," 2014. [Online]. Available: http://epp.eurostat.ec.europa.eu/statistics_explained/index.php/Electricity_and_natural_gas_ price_statistics\#Electricity_prices_for_industrial_consumers. [Accessed: 11-Nov-2014].

[4] A. Poullikkas, G. Kourtis, and I. Hadjipaschalis, "A hybrid model for the optimum integration of renewable technologies in power generation systems," Energy Policy, vol. 39, no. 2, pp. $926-$ 935, Feb. 2011.

[5] European Commission, "EU Reference Scenario 2016 - Energy, transport and GHG emissions Trends to 2050," 2016.

[6] C. Taliotis, M. Howells, M. Bazilian, H. Rogner, and M. Welsch, "Energy Security prospects in Cyprus and Israel: A focus on Natural Gas," Int. J. Sustain. Energy Plan. Manag., vol. 3, no. 0, pp. 5-20, Sep. 2014.

[7] IIASA, "Energy Modeling Framework: Model for Energy Supply Strategy Alternatives and their General Environmental Impact (MESSAGE)," 2012. [Online]. Available:

http://webarchive.iiasa.ac.at/Research/ENE/model/message.html. [Accessed: 16-Dec-2013].

[8] Transmission System Operator - Cyprus, "Yearly Record of Total Generation - Daily Generation 2012," 2014. [Online]. Available:

http://www.dsm.org.cy/nqcontent.cfm?a_id=1778\&tt=graphic\&lang=12. [Accessed: 04-Sep2014].

[9] Transmission System Operator - Cyprus, "Yearly Record of Total Generation - Daily Generation 2013," 2014. [Online]. Available:

http://www.dsm.org.cy/nqcontent.cfm?a_id=1778\&tt=graphic\&lang=12. [Accessed: 04-Sep2014].

[10] Transmission System Operator - Cyprus, "Available Reserve Margin," 2014. [Online]. Available: http://www.dsm.org.cy/nqcontent.cfm?a_id=2891\&tt=graphic\&lang=I2. [Accessed: 11-Jul2014].

[11] EAC, “Annual Report 2012," Electricity Authority of Cyprus, 2013.

[12] Transmission System Operator - Cyprus, "Penetration of Renewable Energy Sources (RES) into the Cyprus Electrical System (2014-2015)," 2016. [Online]. Available:

http://www.dsm.org.cy/media/attachments/RES/RES_PENETRATION_2014-2015_GR.pdf. [Accessed: 26-Aug-2015].

[13] A. Poullikkas, G. Kourtis, and I. Hadjipaschalis, "An overview of the EU Member States support schemes for the promotion of renewable energy sources," Int. J. Energy Environ. Vol 3 Iss 4 Pp 553-566 2012, 2012.

[14] Ministry of Commerce, Industry and Tourism, "National Renewable Energy Action Plan 20102020," Nicosia, Cyprus, Jun. 2010.

[15] European Commission, "2030 framework for climate and energy policies - European Commission," 13-Jan-2015. [Online]. Available:

http://ec.europa.eu/clima/policies/2030/index_en.htm. [Accessed: 10-Feb-2015].

[16] Department of Communications, Energy and Natural Resources and Department of Enterprise, Trade and Investment, "All-Island Grid Study," Dublin, Ireland, Jan. 2008.

[17] IEA, World Energy Outlook 2013. Paris: Organisation for Economic Co-operation and Development, 2013.

[18] A. S. Chuang and C. Schwaegerl, "Ancillary services for renewable integration," in Integration of Wide-Scale Renewable Resources Into the Power Delivery System, 2009 CIGRE/IEEE PES Joint Symposium, 2009, pp. 1-1. 
[19] P. A. Narbel, "Rethinking how to support intermittent renewables," Energy, vol. 77, pp. 414421, Dec. 2014.

[20] M. A. Brown, "Enhancing efficiency and renewables with smart grid technologies and policies," Futures, vol. 58, pp. 21-33, Apr. 2014.

[21] European Commission, "Energy prices and costs report," European Commission, Brussels, SWD(2014) 20 final/2, Mar. 2014.

[22] IEA, Energy Technology Perspectives 2012. Paris: Organisation for Economic Co-operation and Development, 2012.

[23] IRENA, "Southern African Power Pool: Planning and Prospects for Renewable Energy," IRENA, Abu Dhabi, 2013.

[24] IRENA, "West African Power Pool: Planning and Prospects for Renewable Energy," IRENA, Abu Dhabi, 2013.

[25] A. Poullikkas, "Optimization analysis for pumped energy storage systems in small isolated power systems," J. Power Technol., vol. 93, no. 2, pp. 78-89, May 2013.

[26] IRENA, "Electricity Storage and Renewables for Island Power," IRENA, Abu Dhabi, 2012.

[27] IEA, "IEA Energy Prices and Taxes Statistics," OECDiLibrary, 2014. [Online]. Available: http://www.oecd-ilibrary.org/energy/data/iea-energy-prices-and-taxes-statistics_enepricedata-en. [Accessed: 03-Sep-2014].

[28] M. Welsch et al., "Incorporating flexibility requirements into long-term energy system models - A case study on high levels of renewable electricity penetration in Ireland," Appl. Energy, vol. 135, pp. 600-615, Dec. 2014. 


\section{Appendices}

\section{Appendix A: Main Modelling Assumptions}

\section{A.1 Electricity supply system}

Beyond the existing, committed and planned power plant projects mentioned above, future investments in fossil-fuelled and renewable energy technologies are allowed to occur so as to expand the generating capacity of the system, if required, to meet growing demand. Technology options available and assumptions about their parameters can be found in Appendix $B$.

In regards to renewable energy technologies, any installations beyond the existing and committed levels (a total of $50 \mathrm{MW}$ CSP with storage, $15 \mathrm{MW}$ distribution-connected PV under net-metering yearly up to 2020, a total of $175 \mathrm{MW}$ wind by 2018) are simply part of the model's minimum cost pathway to satisfy electricity demand. Generic cost assumptions have been adopted in the analysis, whenever specific data for Cyprus were not available (Figure 5). However, the data is aligned with the situation in Cyprus. For instance, the IEA projects investment costs for rooftop PV in 2014 at 2,900 EUR/kW [22], while at the moment installations in Cyprus cost 1,400-2,000 EUR/kW. Previous IRENA assessments report values that are within this range [23], [24], so IRENA values are adopted for PV (investment cost of $€ 1665 / \mathrm{kW}$ for 2013).

With the assumptions taken on technology costs and performance, as well as fuel prices, solar PV connected at the transmission level appears to be the cheapest electricity generation technology for Cyprus at the moment (Figure 4). Only the Vasilikos combined cycle gas turbines might have a comparable generation cost in the future, depending on the fuel price at which natural gas will be purchased either from external or future domestic suppliers.

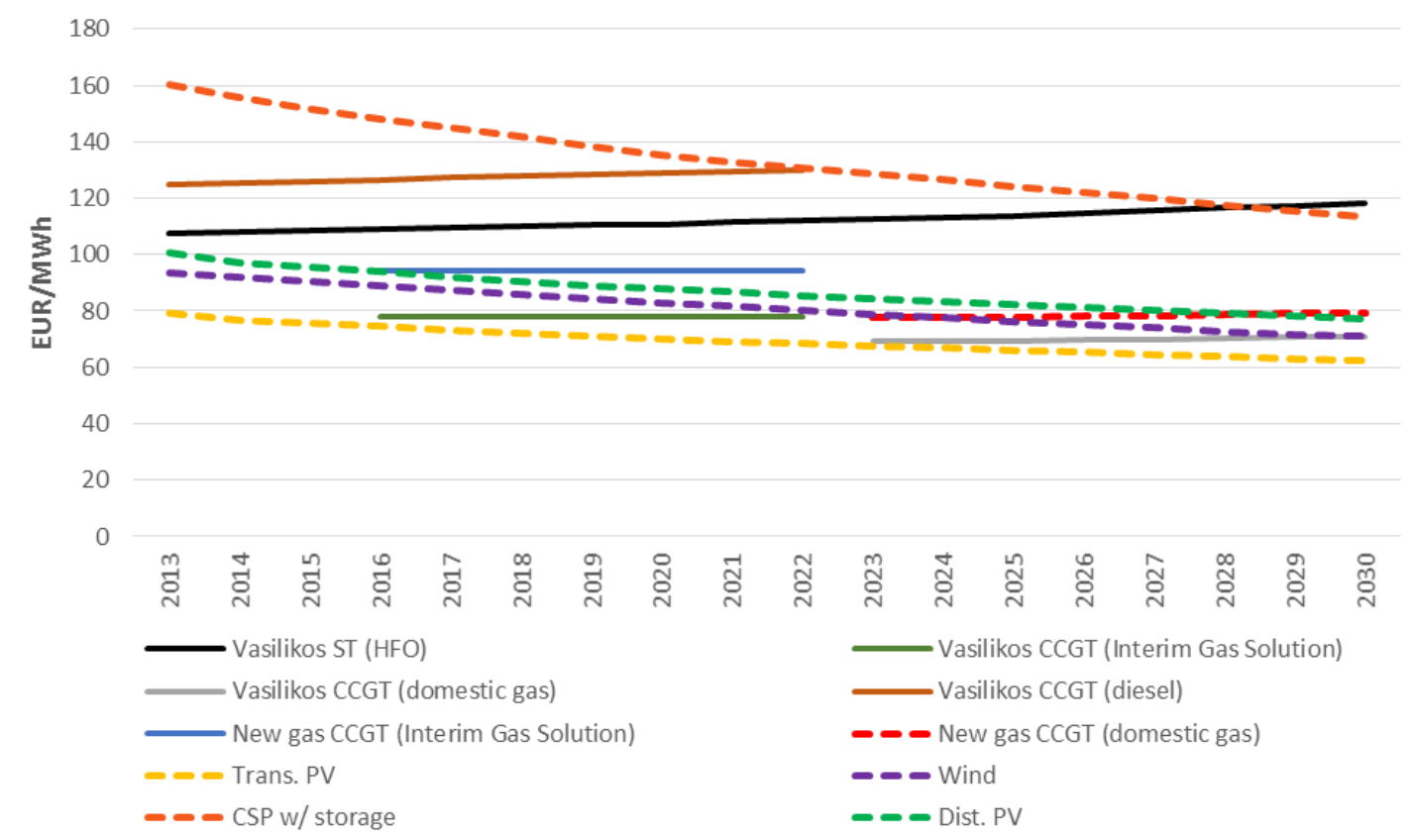

Figure A1. Generation cost comparison: short-run marginal cost for the Vasilikos Power Plant (using different fuels) and longrun marginal cost for new gas CCGT, solar PV, CSP and wind.

Additional to power generating technologies, storage options are considered. The technologies considered in the analysis are pumped-hydro storage [25], flow batteries for transmission-connected storage and Li-ion batteries for storage at the distribution level [26]. Detailed assumptions regarding storage options can be found in Appendix C. 


\section{A.2 Fuel assumptions}

Currently, heavy fuel oil, diesel and small quantities of biomass are the fuels used for power generation in Cyprus. Nonetheless, once natural gas becomes available, it will become the main fuel for power generation, either through the Interim Gas Solution, subject to its economic feasibility, or through domestic production. Recorded fuel prices from the island or from Europe are taken and related to international crude oil prices [27]. Hence, available price projections for crude oil [17] are used to establish price projections for heavy fuel oil, low-S fuel oil and diesel (Table 2).

In order to calculate a reasonable price of gas for the Interim Gas Solution, the assumption as indicated by MECIT is to use a price at which generation cost would be comparable to that of the cheapest renewable energy technology, based on the current price assumptions. As such, the price of imported natural gas (interim gas solution) is set at a level so as the variable cost of generation from the most efficient gas-firing power plants (i.e. existing Vasilikos CCGT) matches that of transmission connected solar PV4. It is assumed that domestic natural gas will be purchased at market price, and thus projections at the European level [17] have been used. Nonetheless, a sensitivity analysis is conducted to investigate the potential effect of a range of gas prices on the generation mix. An additional important assumption was taken in regards to the interim gas solution relating to the volume of gas imports. A limit is imposed on the maximum generation from renewables during the years where imports occur, in order to simulate a take-or-pay agreement, which would force purchase of a minimum volume of gas.

\begin{tabular}{lccccccc}
\multicolumn{2}{l}{ Table A1. Projected fuel prices used in the model } \\
\hline & & $\mathbf{2 0 1 3}$ & $\mathbf{2 0 1 5}$ & $\mathbf{2 0 2 0}$ & $\mathbf{2 0 2 5}$ & $\mathbf{2 0 3 0}$ & $\mathbf{2 0 3 5}$ \\
\hline Oil & USD/barrel & 110 & 111 & 113 & 116 & 121 & 128 \\
& EUR/Mbtu & 14.1 & 14.7 & 15.1 & 15.7 & 16.6 & 14.1 \\
Heavy Fuel Oil & EUR/Mbtu & 11.7 & 11.8 & 12.1 & 12.4 & 12.9 & 13.6 \\
Diesel & EUR/Mbtu & 16.8 & 16.9 & 17.3 & 17.8 & 18.5 & 19.6 \\
Low-S Fuel Oil & EUR/Mbtu & 14.5 & 16.1 & 16.5 & 16.9 & 17.6 & 18.6 \\
$\begin{array}{l}\text { Natural Gas (Int. Market } \\
\text { Price)* }\end{array}$ & EUR/Mbtu & 8.8 & 8.9 & 9.0 & 9.0 & 9.3 & 9.6 \\
\hline
\end{tabular}

* Market Price is aligned with the projected European market price and is the assumed price for domestic use in the power sector [17].

\section{A.3 Concerns regarding system reliability}

Once the share of generation from variable renewable energy technologies increases considerably, concerns regarding system reliability will surface more frequently; especially with a lack of an interconnection to external grid networks. However, if the interconnector with Israel and Greece is developed, Cyprus could gain access to the reserves offered by these countries, provided market design will allow for efficient cross-border trading of electricity and ancillary services. Furthermore, curtailment of electricity from variable renewables can be tackled through exports at a low price. This sub-section details the assumptions taken in the analysis regarding system reliability and reserve requirements.

\section{A.3.1 System operational reserve requirements}

In order to minimize the risk of power shortages caused by rapid changes in power output from variable renewable energy technologies or potential outages of thermal plants, operational reserves

\footnotetext{
${ }^{4}$ In the case of PV costs considered include investment, operation and maintenance costs, while the lifetime, capacity factor and associated discount rate are also taken into account.
} 
are required by the system. A rather conservative approach is taken regarding minimum requirements of fast-response (spinning) reserves. Spinning reserve can be described as online units that can be ramped up or down within seconds or minutes to limit sudden shifts in the frequency of the grid, for example due to outages [28]. Based on information provided by the Transmission System Operator in Cyprus spinning reserve requirements are the following:

- At all times at least $60 \mathrm{MW}$ of spinning reserve needs to be available beyond the level generated to cover demand for electricity.

- An additional reserve corresponding to $50 \%$ of the predicted wind generation should be available.

- In addition to the above, fast-response reserve is needed to account for $10 \%$ of the predicted solar $\mathrm{PV}$ and CSP generation without storage.

In this study, it is assumed that all existing and future centralized thermal plants are allowed to contribute to the above reserves, assuming that all remaining spinning capacity is fast-responsereserves. It is important to note that the proposed interconnector with Greece and Israel, along with associated reserves in the respective countries, may partly contribute to these reserves, but this decision is yet to be made. As such, the aforementioned reserve requirements are kept the same in all scenarios.

\section{A.3.2 System Capacity Reserve Requirements}

In terms of capacity reserve margin no such constraint has been imposed in the model. It is assumed that the renewable energy technologies, the potential interconnector, and the storage facilities cover the security of the system with respect to available capacity of power generation sources to cover the needs of the system. These assumptions need to be re-examined in future analyses, as the contribution to "firm" capacity of each renewable energy technology, storage facilities or the interconnector is evaluated. It should be noted that by extending the lifetime of the existing installations at Vasilikos, Dhekelia and Moni, such a capacity reserve can be maintained well beyond 2030.

\section{A.3.3 Limitations related to the penetration of Solar PV and Wind}

It is beyond the scope of the present study to examine in detail grid integration issues. Therefore, in order to address a potential unrealistic deployment of large shares of variable renewable technologies in the absence of an interconnector, limitations are placed on the amount of solar PV and wind that can enter the system without associated storage:

- The maximum capacity of solar PV without storage is set at $400 \mathrm{MW}$ by 2018.

- The corresponding limit for wind is set at $200 \mathrm{MW}$ by 2018.

These limits are based on preliminary results from a separate study conducted by the Cypriot authorities and these capacities represent respectively $40 \%$ and $20 \%$ of the peak demand for 2018 (CERA, 2014). In the present analysis, these limits are allowed to increase after 2018 following demand growth and maintaining the same share on peak electricity demand. In this sense, the capacity limits reach 550 and $275 \mathrm{MW}$ by 2030 in the Energy Efficiency scenario, and 468 and $234 \mathrm{MW}$ in the Extra Efficiency scenario for solar PV and wind respectively. If these thresholds are reached by the model, no new solar PV without storage or wind can enter the generation mix. Instead, the system can either

- invest in decentralized storage options of $1 \mathrm{kWp}$ for each $1 \mathrm{kWp}$ of distribution-connected solar $\mathrm{PV}$; or

- invest in transmission connected storage (i.e. pumped hydro storage or flow batteries). For instance in case $130 \mathrm{MW}$ pumped hydro storage is deployed, an additional $130 \mathrm{MW}$ of solar PV or wind can be installed. 
These are simplified assumptions based on the best available information at the time of the study. A detailed grid model is under development by the Joint Research Centre of the European Commission. Based on the findings of this grid study, an update of the model can be developed, and a suite of grid integration measures that can be adopted will be assessed. Specific issues related to grid codes and market design will also influence the amount to variable renewables that can be integrated. 
Appendix B: Detailed Power Plant Assumptions for Future Projects

Table B1 - Plant cost and performance parameters for future projects.

\begin{tabular}{|c|c|c|c|c|c|c|c|c|c|}
\hline Technology Type & Input Fuel & Efficiency & $\begin{array}{l}\text { Variable Operation } \\
\text { and Maintenance } \\
\text { Cost (EUR / MWh) }\end{array}$ & $\begin{array}{l}\text { Fixed } \\
\text { Operation and } \\
\text { Maintenance } \\
\text { Cost } \\
(\text { EUR/kW) }\end{array}$ & $\begin{array}{c}2013 \text { Inv } \\
\text { Cost (EUR } \\
\text { /kW) }\end{array}$ & $\begin{array}{l}\text { Capacity } \\
\text { factor }\end{array}$ & $\begin{array}{l}\text { First } \\
\text { Year }\end{array}$ & $\begin{array}{l}\text { Construction } \\
\text { Time (years) }\end{array}$ & $\begin{array}{c}\text { Plant Life } \\
\text { (years) }\end{array}$ \\
\hline Combined Cycle & Gas & $47.50 \%$ & & 33.1 & 828 & $86.02 \%$ & 2019 & 3 & 30 \\
\hline Gas Turbine & Diesel/Gas & $44.00 \%$ & & 27.1 & 677 & $82.80 \%$ & 2019 & 2 & 30 \\
\hline Steam Turbine & $\begin{array}{l}\text { HFO or } \\
\text { Low-S FO }\end{array}$ & $38.46 \%$ & & 27.1 & 1,016 & $80.10 \%$ & 2019 & 2 & 30 \\
\hline Wind & & & 14.3 & & 1,310 & $16.00 \%$ & 2015 & 1 & 25 \\
\hline Biomass & & $32.00 \%$ & & 75.3 & 2,800 & $48.50 \%$ & 2015 & 2 & 25 \\
\hline Solar PV utility & & & 15.1 & & 1,332 & $18.50 \%$ & 2015 & 1 & 25 \\
\hline Solar PV rooftop & & & 11.3 & & 1,665 & $18.50 \%$ & 2014 & $<1$ & 20 \\
\hline CSP w/ storage & & & 21.8 & & 6,200 & $39.25 \%$ & 2017 & 2 & 25 \\
\hline
\end{tabular}


Table B2 - RE technology investment cost projections.

\begin{tabular}{lccccccccc}
\hline & \multicolumn{10}{c}{ EUR/kW } \\
\hline Wind & $\mathbf{2 0 1 3}$ & $\mathbf{2 0 1 4}$ & $\mathbf{2 0 1 5}$ & $\mathbf{2 0 1 6}$ & $\mathbf{2 0 1 7}$ & $\mathbf{2 0 1 8}$ & $\mathbf{2 0 1 9}$ & $\mathbf{2 0 2 0}$ & $\mathbf{2 0 2 1}$ \\
\hline Biogas-biomass & 1,417 & 1,389 & 1,361 & 1,334 & 1,307 & 1,281 & 1,255 & 1,230 & 1,205 \\
\hline Solar PV utility & 2,800 & 2,748 & 2,695 & 2,643 & 2,590 & 2,537 & 2,485 & 2,432 & 2,406 \\
\hline PV rooftop & 1,332 & 1,279 & 1,253 & 1,228 & 1,203 & 1,179 & 1,156 & 1,138 & 1,121 \\
\hline CSP w/ storage & 1,665 & 1,598 & 1,566 & 1,535 & 1,504 & 1,474 & 1,445 & 1,423 & 1,402 \\
& 6,200 & 6,009 & 5,818 & 5,679 & 5,541 & 5,403 & 5,264 & 5,126 & 5,032 \\
\hline Wind & $\mathbf{2 0 2 2}$ & $\mathbf{2 0 2 3}$ & $\mathbf{2 0 2 4}$ & $\mathbf{2 0 2 5}$ & $\mathbf{2 0 2 6}$ & $\mathbf{2 0 2 7}$ & $\mathbf{2 0 2 8}$ & $\mathbf{2 0 2 9}$ & $\mathbf{2 0 3 0}$ \\
\hline Biogas-biomass & 1,181 & 1,158 & 1,135 & 1,112 & 1,090 & 1,068 & 1,046 & 1,026 & 1,020 \\
\hline Solar PV utility & 2,380 & 2,353 & 2,327 & 2,301 & 2,275 & 2,248 & 2,222 & 2,196 & 2,169 \\
\hline PV rooftop & 1,105 & 1,088 & 1,072 & 1,056 & 1,040 & 1,024 & 1,009 & 994 & 984 \\
\hline CSP w/ storage & 1,381 & 1,360 & 1,340 & 1,320 & 1,300 & 1,280 & 1,261 & 1,242 & 1,230 \\
\hline
\end{tabular}


Appendix C: Detailed Electrical Storage Assumptions

Table C1 - Pumped-hydro storage specifications [25].

\begin{tabular}{ll}
\hline Location of Facility & Kourris Dam \\
\hline Year of Operation & 2021 \\
\hline Nominal Capacity (MW) & 130 \\
\hline Overall efficiency & $77 \%$ \\
\hline Full load operation for electricity production & 88 hours \\
\hline Capital cost (EUR/kW) & 1,185 \\
\hline O\&M cost (EUR/kW-yr) & 11 \\
\hline
\end{tabular}

Table C2 - Battery options for electrical storage [26].

\begin{tabular}{lll}
\hline & Flow Batteries & Li-lon Batteries \\
\hline Level & Centralized & Decentralized \\
First Year of Operation & 2016 & 2016 \\
Capital cost EUR/kW & 828 & 527 \\
\hline Capital cost EUR/kWh cap & 433 & 753 \\
$\begin{array}{l}\text { Fixed OM costcost } \\
\text { EUR/kW-yr }\end{array}$ & 22.6 & 18.8 \\
Efficiency & $77.5 \%$ & $90 \%$ \\
Lifetime (yrs) & 10 & 12.5 \\
Lifetime (charge cycles) & $1,500-15,000$ & $2,000-3,000$ \\
\hline
\end{tabular}

